\title{
Electron Attachment Step in Electron Capture Dissociation (ECD) and Electron Transfer Dissociation (ETD)
}

\author{
Iwona Anusiewicz, Joanna Berdys-Kochanska, and Jack Simons* \\ Chemistry Department and Henry Eyring Center for Theoretical Chemistry, University of Utah, \\ Salt Lake City, Utah 84112 \\ Received: January 12, 2005; In Final Form: May 10, 2005
}

\begin{abstract}
We have made use of classical dynamics trajectory simultions and ab initio electronic structure calculations to estimate the cross sections with which electrons are attached (in electron capture dissociation (ECD)) or transferred (in electron transfer dissociation (ETD)) to a model system that contained both an $\mathrm{S}-\mathrm{S}$ bond that is cleaved and $\mathrm{a}-\mathrm{NH}_{3}{ }^{+}$positively charged site. We used a Landau-Zener-Stueckelberg curve-crossing approximation to estimate the ETD rates for electron transfer from a $\mathrm{CH}_{3}{ }^{-}$anion to the $-\mathrm{NH}_{3}{ }^{+} \mathrm{Rydberg}^{-}$ orbital or the $\mathrm{S}-\mathrm{S} \sigma^{*}$ orbital. We draw conclusions about ECD from our ETD results and from known experimental electron-attachment cross sections for cations and $\sigma$-bonds. We predict the cross section for ETD at the positive site of our model compound to be an order of magnitude larger than that for transfer to the Coulomb-stabilized $\mathrm{S}-\mathrm{S}$ bond site. We also predict that, in ECD, the cross section for electron capture at the positive site will be up to 3 orders of magnitude larger than that for capture at the $S-S$ bond site. These results seem to suggest that attachment to such positive sites should dominate in producing $\mathrm{S}-\mathrm{S}$ bond cleavage in our compound. However, we also note that cleavage induced by capture at the positive site will be diminished by an amount that is related to the distance from the positive site to the $S-S$ bond. This dimunition can render cleavage through Coulomb-assisted $\mathrm{S}-\mathrm{S} \sigma^{*}$ attachment competitive for our model compound. Implications for ECD and ETD of peptides and proteins in which SS or $\mathrm{N}-\mathrm{C}_{\alpha}$ bonds are cleaved are also discussed, and we explain that such events are most likely susceptible to Coulomb-assisted attachment, because the $\mathrm{S}-\mathrm{S} \sigma^{*}$ and $\mathrm{C}=\mathrm{O} \pi^{*}$ orbitals are the lowest-lying antibonding orbitals in most peptides and proteins.
\end{abstract}

\section{Introduction}

In electron capture dissociation (ECD) mass spectrometry experiments, ${ }^{1}$ very low-energy electrons attach to a gaseous multiply positively charged protein or peptide ion to generate very characteristic backbone bond cleavages. The fact that primarily $\mathrm{N}-\mathrm{C}_{\alpha}$ and $\mathrm{S}-\mathrm{S}$ bonds are cleaved throughout much of the backbone is a great strength of the ECD method, because so many fragment ions resulting from these two specific cleavages are produced. The result is a wealth of information that can be used for protein sequencing. More recently, a variant of ECD, termed electron transfer dissociation (ETD), has also shown promise, ${ }^{2}$ because it does not require the highly sophisticated and expensive Fourier transform-ion cyclotron resonance (FT-ICR) instrumentation of ECD. In ETD, one uses collisions with a molecular anion $\left(\mathrm{A}^{-}\right)$to transfer an electron to the peptide or protein cation. This produces a less-exothermic (i.e., more "gentle") electron-transfer reaction than that in ECD. ${ }^{3}$

Although the fragmentation patterns characteristic of ECD and ETD are largely known (i.e., $\mathrm{N}-\mathrm{C}_{\alpha}$ and $\mathrm{S}-\mathrm{S}$ bond cleavages dominate), the mechanisms by which these two processes occur is still under investigation. ${ }^{4}$ The present work is intended to further elucidate some of the possible mechanisms that may be operative.

A. Review of the Electron Capture Dissociation Mechanisms That Have Been Proposed. Let us briefly review what is believed to occur ${ }^{1,4}$ in the ECD fragmentation of $\mathrm{N}-\mathrm{C}_{\alpha}$ and

* Corresponding author. E-mail address: simons@chemistry.utah.edu.
$\mathrm{S}-\mathrm{S}$ bonds in peptides and proteins. Most workers agree that the positively charged sites in the cation sample have a central role in attracting and binding the low-energy (ECD) or weakly bound (ETD) electron. Two variants of a mechanism used to explain ECD findings are shown in Scheme 1a and $b$.

In the variant ${ }^{1}$ depicted in Scheme 1a, an electron is attached (or transferred, in the case of ETD) to a protonated site of the parent cation to form a so-called Rydberg or hypervalent radical (II), after which several steps occur. The energy generated in the electron capture event (ca. $3.5 \mathrm{eV}$ or more) can, as the nascent Rydberg radical undergoes internal conversion to lowerenergy Rydberg states, eject a hydrogen radical with substantial kinetic energy. This hot $\mathrm{H}$ atom can, if properly directed when ejected, strike the $\mathrm{C}=\mathrm{O} \pi$-bond and overcome a ca. $40-68 \mathrm{~kJ} /$ mol barrier ${ }^{4 b, 4 d, 5}$ to form a $\mathrm{C}-\mathrm{OH}$ radical (III). If the nascent Rydberg radical relaxes all the way to the ground Rydberg state (e.g., by distributing the exothermicity radiationlessly to vibrational modes), the elimination of a much colder hydrogen radical can occur by surmounting only a $10-15 \mathrm{~kJ} / \mathrm{mol}$ barrier. ${ }^{4 \mathrm{~b}}$ However, such a cold $\mathrm{H}$ atom will not be able to surmount the $40-68 \mathrm{~kJ} / \mathrm{mol}$ barrier to form the $\mathrm{C}-\mathrm{OH}$ radical. After any $\mathrm{C}-\mathrm{OH}$ radical is formed, the radical III can then break its $\mathrm{N}-\mathrm{C}_{\alpha}$ bond (but must overcome a barrier to do so) to form the characteristic $\mathrm{c}$ and $\mathrm{z}$ fragments observed in ECD.

In the variant ${ }^{4}$ depicted in Scheme $1 \mathrm{~b}$, the $-\mathrm{NH}_{3}{ }^{+}$site is involved in an interaction (e.g., a hydrogen bond) with the carbonyl $\mathrm{O}$ atom when the electron (or the anion, for ETD) strikes and attaches to the $-\mathrm{NH}_{3}{ }^{+}$. A proton-coupled electron- 


\section{SCHEME 1}

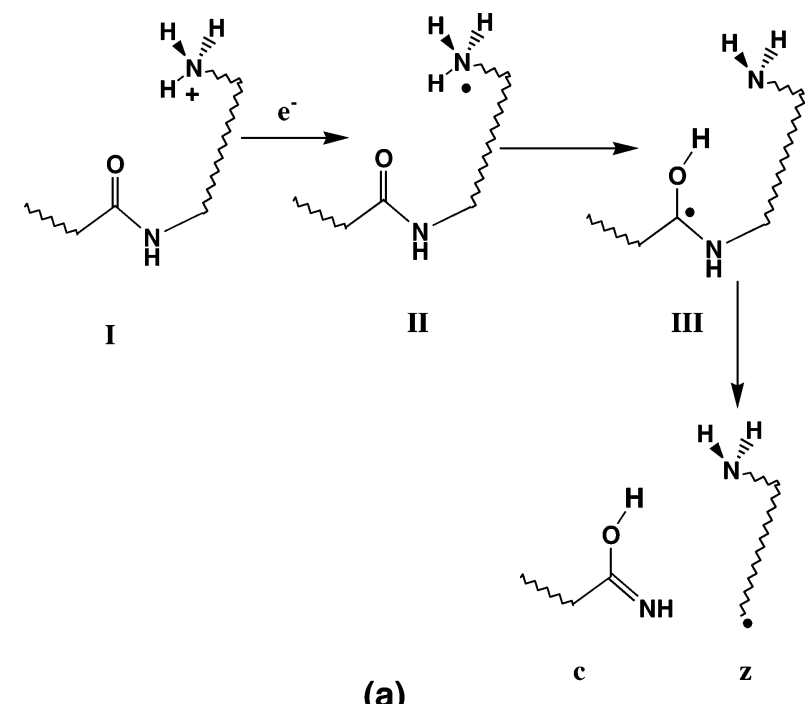

(a)

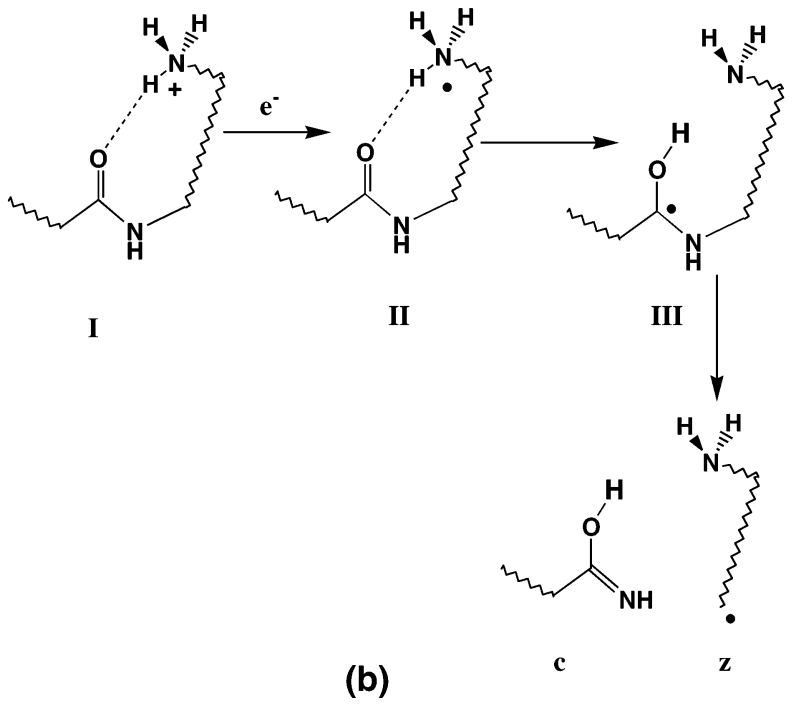

transfer event then occurs, in which the $\mathrm{N}-\mathrm{H}$ bond directed toward the carbonyl oxygen elongates as the $\mathrm{H}-\mathrm{O}$ distance decreases, thereby generating the $\mathrm{C}-\mathrm{OH}$ radical in a reaction that has been estimated ${ }^{5}$ to be $66 \mathrm{~kJ} / \mathrm{mol}$ exothermic. This concerted process has been shown to have a lower barrier ${ }^{5}$ than does the sequential process involving $\mathrm{H}$-atom loss from the ground-state $-\mathrm{NH}_{3}$ radical, followed by attack of $\mathrm{C}=\mathrm{O}$, which argues in favor of Scheme 1b over Scheme 1a.

Another interpretation of Scheme $1 b^{1}$ involves attaching (or transferring) an electron to a high-lying Rydberg state that lives long enough ${ }^{6}$ to permit the $-\mathrm{NH}_{3}$ site to subsequently move near enough to the carbonyl oxygen to allow transfer of a $\mathrm{H}$ atom to form the $\mathrm{C}-\mathrm{OH}$ radical and to deposit sufficient energy in the region of this radical to allow the barrier to $\mathrm{N}-\mathrm{C}_{\alpha}$ bond cleavage to be overcome. In this view, the high-lying Rydberg state serves to "store" the attached electron until geometrical motions allow the two important sites to achieve some critical distance (and perhaps orientation). The high Rydberg state may, by interacting with the $\mathrm{C}=\mathrm{O}$ bond, also serve to assist in making this bond more susceptible to $\mathrm{H}$-atom attack.

An analogous set of mechanistic ideas have been presented ${ }^{1,4,5}$ to explain how $\mathrm{S}-\mathrm{S}$ bond cleavage occurs in ECD; these ideas are summarized in Scheme 2. Again, there may be differences in the details of how various workers interpret this mechanism;

\section{SCHEME 2}
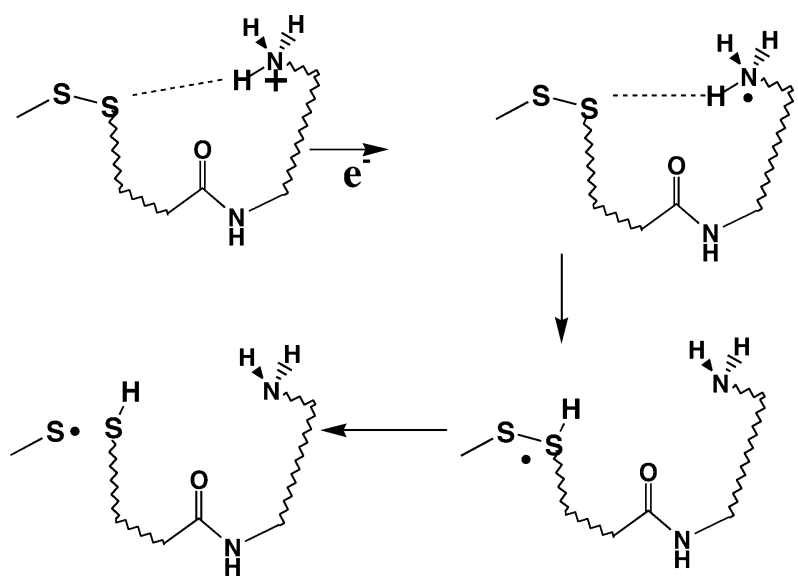

however, it is clear that the positive site and its interaction with the $\mathrm{S}-\mathrm{S}$ bond are suggested to have central roles.

What characterizes all of the most commonly quoted mechanisms ${ }^{1,4,5}$ for ECD? Such characterization has the following requirements:

(1) That the positive sites attract and bind the electron, and, because of the higher proton affinities of the amine groups, these positive sites are more likely to occur on amine groups than on the carbonyl $\left(\mathrm{C}=\mathrm{OH}^{+}\right)$or $\mathrm{SS}\left(-\mathrm{SSH}_{-}^{+}\right)$groups to which an $\mathrm{H}$ atom eventually binds.

(2) That H-atom attack is likely involved (because of the high $\mathrm{H}$-atom affinities of the $\mathrm{C}=\mathrm{O}$ and $\mathrm{S}-\mathrm{S}$ groups) in generating the $\mathrm{C}-\mathrm{OH}$ or $\mathrm{S}-\mathrm{H}$ groups that occur in the fragment ions.

(3) That the proximity of the positive sites to the $\mathrm{C}=\mathrm{O}$ or $\mathrm{S}-\mathrm{S}$ groups is important (either in establishing an interaction to the $\mathrm{C}=\mathrm{O}$ or $\mathrm{S}-\mathrm{S}$ bond to assist transfer of a $\mathrm{H}$ atom or being close enough for a $\mathrm{H}$ atom ejected from $-\mathrm{NH}_{3}{ }^{+}$to be able to reach the $\mathrm{S}-\mathrm{S}$ or $\mathrm{C}=\mathrm{O}$ bond).

B. Results That Seem To Suggest an Additional Mechanism. Our interest in the ECD process began when findings of the Marshall group ${ }^{7}$ seemed to suggest that mechanisms in addition to those previously discussed might be involved. In these experiments, a series of lysine-protonated dimers of AcCys $-\mathrm{Ala}_{n}-\mathrm{Lys}\left(\mathrm{AcCA}_{n} \mathrm{~K}+\mathrm{H}\right)_{2}{ }^{2+}$ was subjected to ECD; each of these protonated dimers have two monomers that contain (i) $n=10,15$, or 20 alanines labeled A (shown forming helices in Figure 1 for the $n=15$ case), (ii) a cysteine labeled C (shown in the center involved in an $\mathrm{S}-\mathrm{S}$ bond to the other cysteine of the dimer and linked to the helical alanines), and (iii) a singly protonated lysine labeled $\mathrm{K}+\mathrm{H}$ (shown at the termini and joined to the helical alanines).

What was especially surprising about the findings of ref 7 , given the mechanism shown in Scheme 2 for $S-S$ bond cleavage, were the following facts:

(1) $S-S$ cleavage was the dominant event, when 10,15 , or 20 alanine units were present. In the case with 20 alanines, the distance from the positively charged amine sites on the lysines and the $\mathrm{S}-\mathrm{S}$ bond is ca. $30 \AA$. One clearly wonders how the $\mathrm{H}$ atom that is ejected (hot or cold) from the terminal lysine sites

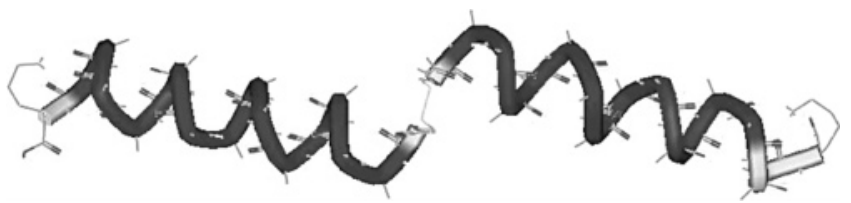

Figure 1. Structure of an $\left(\mathrm{AcCA}_{15} \mathrm{~K}+\mathrm{H}\right)_{2}{ }^{2+}$ disulfide-linked dimer (from ref 7). 
can find its way to the $\mathrm{S}-\mathrm{S}$ bond when the distance is so large. One also wonders how a high-lying Rydberg orbital localized on the lysine site could assist in (efficiently) transferring an $\mathrm{H}$ atom to a $\mathrm{S}-\mathrm{S}$ bond that is $30 \AA$ away. Certainly, the overlap of such a large Rydberg orbital with the $\mathrm{S}-\mathrm{S}$ bond's $\sigma^{*}$ orbital would decrease as the distance (i.e., the number of alanine units) increased. It has been suggested ${ }^{8}$ that the alanine units may not be as helically arranged as shown in Figure 1 and that the terminal lysine chains may therefore be able to come sufficiently close to the $\mathrm{S}-\mathrm{S}$ bond to effect $\mathrm{H}$-atom transfer, as in Scheme 1. However, ion mobility measurements ${ }^{9}$ suggest that the extended helical structure shown in Figure 1 is likely what is present in the ECD experiments of ref 7.

(2) Even when the species shown in Figure 1 has its two positive lysine units replaced by sodiated amine groups (i.e, $\mathrm{K}+\mathrm{H}$ replaced by $\left.-\mathrm{NH}_{2} \mathrm{Na}^{+}\right)$to give $\left(\mathrm{AcCA}_{15} \mathrm{NH}_{2} \mathrm{Na}\right)_{2}{ }^{2+}, \mathrm{S}-\mathrm{S}$ bond cleavage was found (ref 7) to be the main fragmentation under ECD conditions. Because the Na-atom affinity of $S-S$ bonds is not nearly that of their $\mathrm{H}$-atom affinities, it is difficult to explain how $\mathrm{S}-\mathrm{S}$ bond cleavage can occur. It has been suggested ${ }^{8}$ that $\mathrm{H}$ atoms could be ejected from the $-\mathrm{NH}_{2} \mathrm{Na}$ groups after $\mathrm{NH}_{2} \mathrm{Na}^{+}$is rendered neutral by electron attachment; however, this seems unlikely to us, based on the fact that the $\mathrm{Na}^{+}$affinity of $-\mathrm{NH}_{2}$ is less than the proton affinity of $-\mathrm{NH}_{2}$, so it seems much more likely that sodium would be ejected than hydrogen.

Therefore, it seemed apparent to us that something more must be happening in ECD cleavage of $\mathrm{S}-\mathrm{S}$ bonds (and perhaps in $\mathrm{N}-\mathrm{C}_{\alpha}$ bond cleavage, as we discuss later). In our initial investigations ${ }^{10}$ into these matters, we considered the possibility that the Coulomb potentials produced by any positive site(s) (e.g, be they $-\mathrm{NH}_{3}{ }^{+}$sites on lysine or A- $\mathrm{NH}_{2} \mathrm{Na}^{+}$sites) could lower the antibonding $\mathrm{S}-\mathrm{S} \sigma^{*}$ orbitals ${ }^{11}$ to an extent that would render direct electron attachment into such orbitals exothermic. We were aware that dissociative electron attachment (DEA) experiments showed ${ }^{12}$ that direct vertical attachment of an electron to a $\mathrm{S}-\mathrm{S} \sigma^{*}$-orbital was endothermic by $0.5-1.0 \mathrm{eV}$ (depending on the nature of the groups attached to the two $S$ atoms). Because ECD conditions do not contain (many) such electrons, it seems unlikely that direct DEA could be occurring.

We should note that we were not the first to consider the idea that nearby positive charges could alter electron attachment energetics. We note that, in 1997, Berges et al., ${ }^{13}$ in an investigation of lysozyme reduction, theoretically studied adding an electron to a model system that involved a guanidinium cation $\left(\left(\mathrm{NH}_{2}\right)_{3} \mathrm{C}^{+}\right)$in close proximity to an $\mathrm{HSSH}$ molecule. The $\left(\mathrm{NH}_{2}\right)_{3} \mathrm{C}^{+}$ion alone was shown to bind an electron by ca. 3 $\mathrm{eV}$, and, of course, the HSSH is unstable, with respect to vertical electron attachment (by ca. $0.9 \mathrm{eV}$ ). In the study of ref 13 , it was observed that an electron could bind either to the $\left(\mathrm{NH}_{2}\right)_{3} \mathrm{C}^{+}$ site of the $\left(\mathrm{NH}_{2}\right)_{3} \mathrm{C}^{+} \cdot . \cdot \mathrm{HSSH}$ complex or to the HSSH site. The latter they viewed as a zwitterion having the character $\left(\mathrm{NH}_{2}\right)_{3} \mathrm{C}^{+} \cdot \cdots \mathrm{HSSH}^{-}$, but they did not make the observation that the electron was bound in the $\mathrm{S}-\mathrm{S} \sigma^{*}$-orbital. We should also note that, in ref $1 \mathrm{c}$, it was suggested that positive charges near $\mathrm{S}-\mathrm{S}$ bonds might increase the electron affinities of such species, although, again, the role of the $\mathrm{S}-\mathrm{S} \sigma^{*}$-orbital was not discussed. It is our belief that we were the first to suggest that Coulomb potentials could stabilize such $\sigma^{*}$-orbitals to an extent that would render direct vertical electron attachment exothermic.

\section{Review of Our Earlier Studies on Coulomb-Assisted $\mathrm{S}-\mathrm{S}$ and $\mathrm{N}-\mathrm{C}_{\alpha}$ Bond Cleavage}

In one of our recent studies ${ }^{10 \mathrm{~b}}$ of how electrons might bind directly and exothermically to $\mathrm{S}-\mathrm{S}$ bonds, we considered the
PATHWAY 1. Fragmentation Beginning with Attachment to the Positive Site.

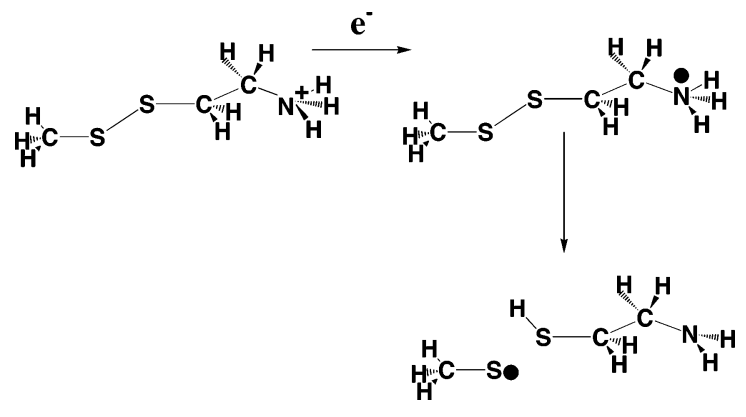

PATHWAY 2. Fragmentation Beginning with Attachment to the $S-S \sigma^{*}$-Orbital.

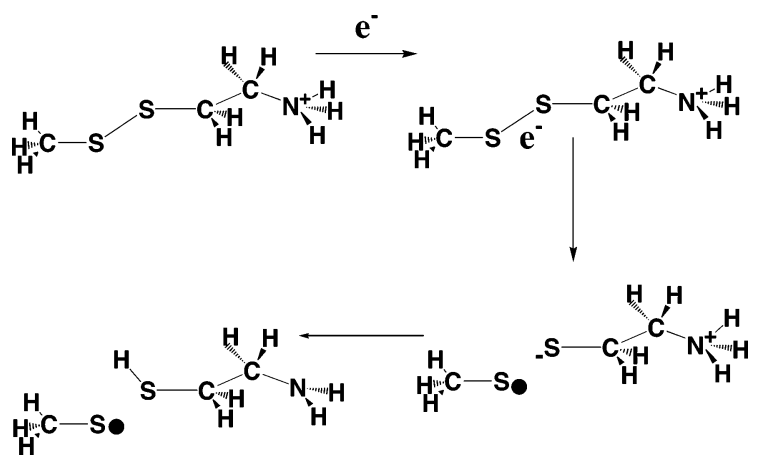

small positively charged molecule shown below, where we also show the two fragmentation pathways that we examined. This molecule was chosen because the distance between the positive site and the midpoint of the $\mathrm{S}-\mathrm{S}$ bond (ca. $4.8 \AA$ ) makes the Coulomb potential at the $\mathrm{S}-\mathrm{S}$ bond ca. $3 \mathrm{eV}$. This stabilizing potential then renders the $\mathrm{S}-\mathrm{S} \sigma^{*}$ state, to which it is $0.9 \mathrm{eV}$ endothermic to attach an electron in the absence of any such potential, exothermic by $2 \mathrm{eV}$ for electron attachment. In addition, this molecule is small enough to allow us to perform reasonably reliable ab initio calculations on it.

Our primary findings of ref $10 \mathrm{~b}$ are summarized in Figure 2. The essential points to be gleaned from Figure 2 are as follows:

(1) The Rydberg-attached species lies (vertically) ca. $4 \mathrm{eV}$ below the parent and its energy varies with $S-S$ bond length in a manner that tracks that of the parent, as expected, because having an electron in the Rydberg orbital hardly alters the $S-S$ bonding.

(2) This Rydberg-attached species can undergo an intramolecular $\mathrm{H}$-atom migration along a path in which the $\mathrm{S}-\mathrm{S}$ bond length is not the only primary component to the reaction coordinate. This migration begins with elongation of one $\mathrm{N}-\mathrm{H}$ bond, moving the $\mathrm{H}$ atom over a small barrier (labeled " 1 " in Figure 2) and onto an $\mathrm{S}$ atom to generate the $\mathrm{MeSS}^{\bullet}(\mathrm{H}) \mathrm{CH}_{2} \mathrm{CH}_{2}-$ $\mathrm{NH}_{2}$ radical (the point labeled " 2 " in Figure 2), which then evolves over another low barrier (labeled "3") by stretching the $\mathrm{S}-\mathrm{S}$ bond to generate the $\mathrm{MeS}^{\bullet}$ radical and the closed-shell $\mathrm{HSCH}_{2} \mathrm{CH}_{2}-\mathrm{NH}_{2}$ (the point labeled "4"). Because the transition states involved in these $\mathrm{N}-\mathrm{H}$ and $\mathrm{S}-\mathrm{S}$ bond movements are low in energy, the net result is facile fragmentation of the Rydberg-attached species to produce $\mathrm{MeS}^{\bullet}$ and $\mathrm{HSCH}_{2} \mathrm{CH}_{2}-$ $\mathrm{NH}_{2}$.

(3) The $\mathrm{S}-\mathrm{S} \sigma^{*}$ attached species vertically lies below the parent by ca. $2 \mathrm{eV}$ (as expected based on considerations of Coulomb stabilization) and is spontaneously dissociative to generate the $\mathrm{MeS}$ radical and the ${ }^{-} \mathrm{S}-\mathrm{CH}_{2}-\mathrm{CH}_{2}-\mathrm{NH}_{3}{ }^{+}$ zwitterions (drawn in the right-hand margin of the $\mathrm{S}-\mathrm{S} \sigma^{*}$ curve 


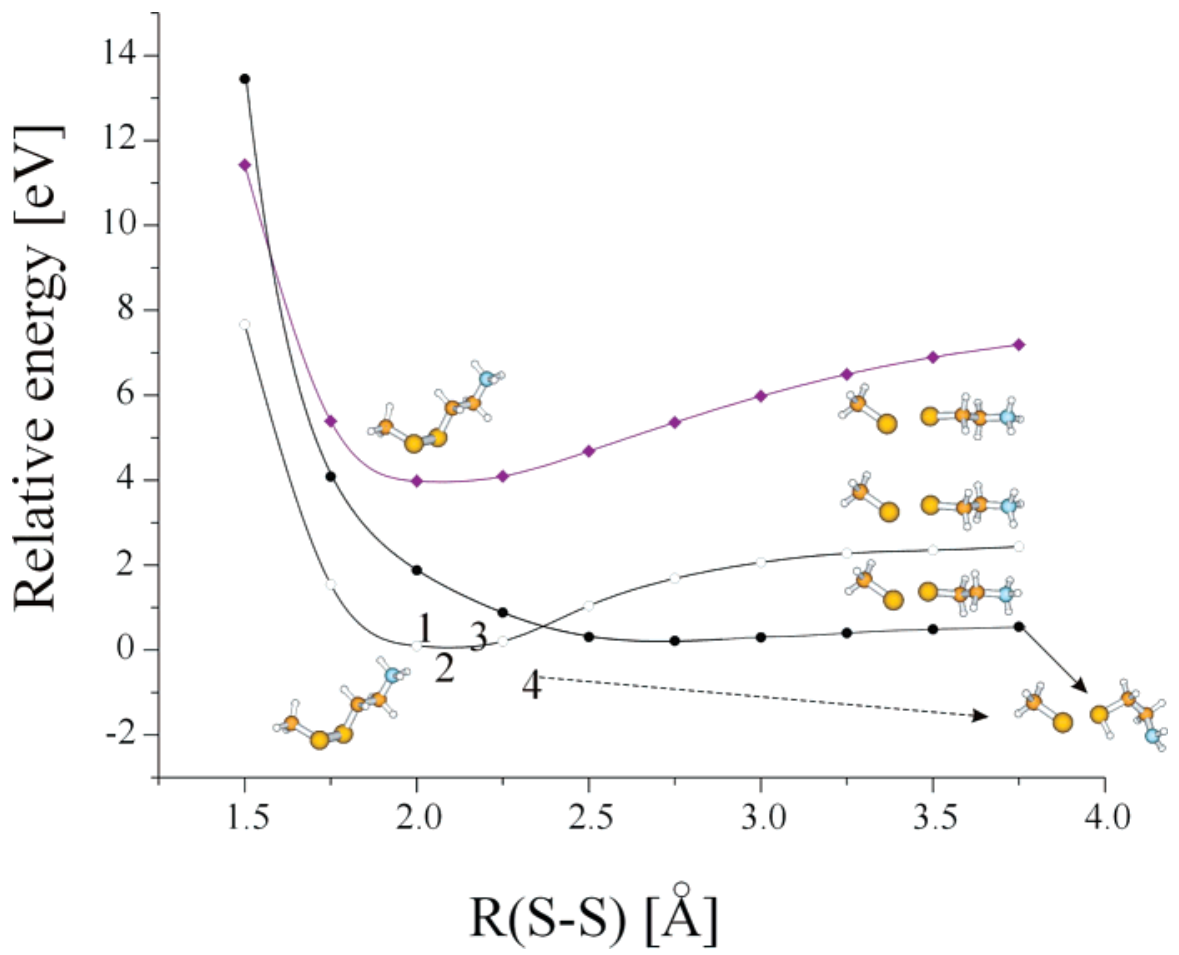

Figure 2. Energies of $(\diamond)$ the parent $\mathrm{MeSSCH}_{2} \mathrm{CH}_{2}-\mathrm{NH}_{3}{ }^{+}$species, $(\mathrm{O})$ the Rydberg-attached species, and $(\bullet)$ the $\mathrm{S}-\mathrm{S} \sigma^{*}$-attached species, each as a function of the $\mathrm{S}-\mathrm{S}$ bond length (as shown in ref $10 \mathrm{~b}$ ). The Rydberg-attached species also can fragment along a path $(1,2,3,4)$, as detailed in the text.

SCHEME 3

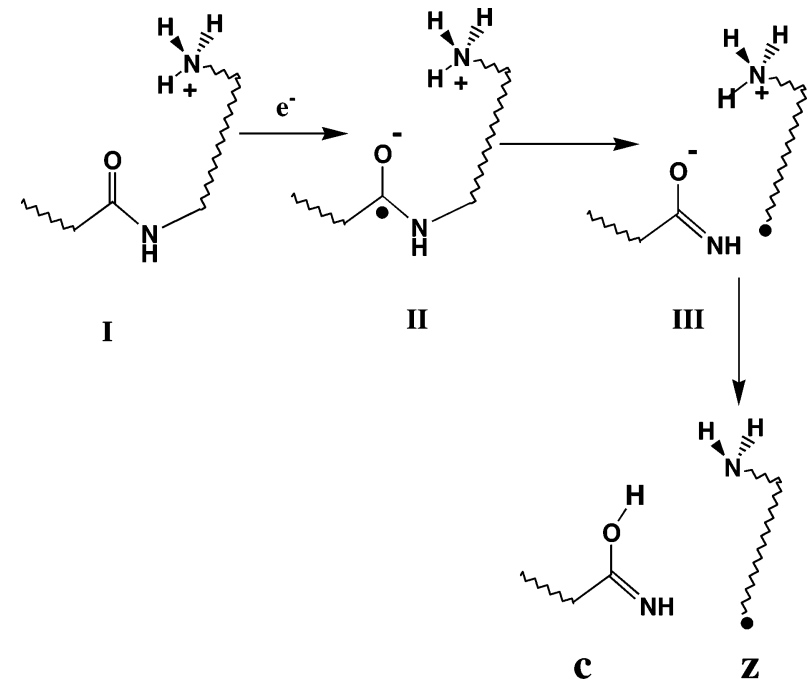

in Figure 2). The latter species spontaneously rearranges by way of an intramolecular proton migration to produce $\mathrm{HS}-\mathrm{CH}_{2}-$ $\mathrm{CH}_{2}-\mathrm{NH}_{2}$, as indicated by the solid arrow shown at the right margin in Figure 2.

In addition to examining the feasibility of direct electron attachment to $\mathrm{S}-\mathrm{S}$ bonds, as previously discussed, we also considered ${ }^{14}$ the possibility that electrons could attach exothermically to carbonyl $\pi^{*}$-orbitals to induce $\mathrm{N}-\mathrm{C}_{\alpha}$ bond cleavage via a pathway such as that shown in Scheme 3.

Near the equilibrium $\mathrm{C}=\mathrm{O}$ bond length, a $\mathrm{C}=\mathrm{O} \pi^{*}$-orbital is ca. $2.8 \mathrm{eV}$ unstable (ref 14), with respect to vertical electron attachment, as shown in Figure 3b, where we show results that we obtained for the model peptide shown in Figure $3 \mathrm{a}$.

In the data displayed in Figure $3 \mathrm{~b}$ for the model peptide shown in Figure 3a, there is no stabilizing Coulomb potential present, so direct vertical electron attachment is ca. $2.8 \mathrm{eV}$
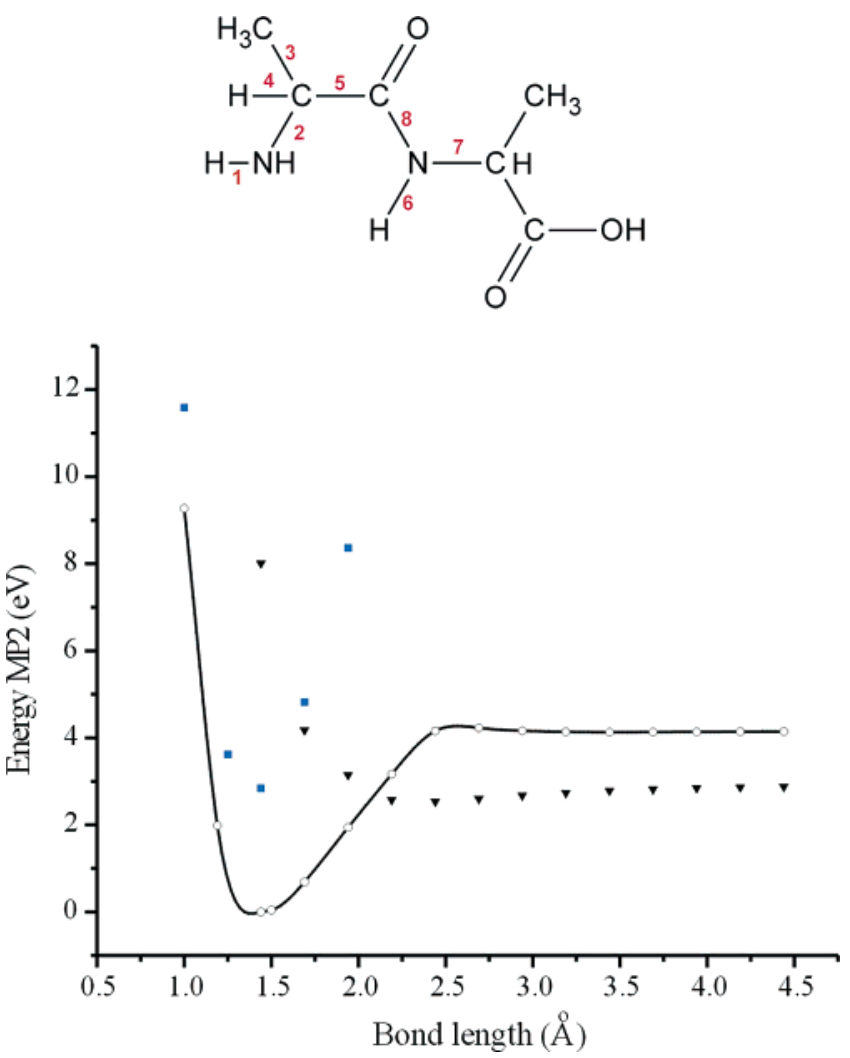

Figure 3. (a) Model peptide used in ref 14. (b) Energies of (-O-) the parent species, $(\mathbf{\square}) \pi^{*}$-attached species, and $(\mathbf{\Lambda}) \sigma^{*}$-attached species for the model peptide from ref 14 (Figure 3a), each as a function of the $\mathrm{N}-\mathrm{C}_{\alpha}$ bond length.

endothermic, as mentioned previously. However, when any positive site is within $5 \AA$ of the $\mathrm{C}=\mathrm{O} \pi$-bond, its stabilizing Coulomb potential will lower the $\pi^{*}$ - and $\sigma^{*}$-curves shown in Figure $3 b$ by amounts that will render direct vertical attachment into the $\mathrm{C}=\mathrm{O} \pi^{*}$-orbital exothermic. After an electron enters 
the $\pi^{*}$-orbital, forming the species labeled II in Scheme 3 , the $\mathrm{N}-\mathrm{C}_{\alpha}$ bond can be broken by passing over the barrier formed by the $\pi^{*} / \sigma^{*}$ curve crossing in Figure 3 to produce species III in Scheme 3. This nascent zwitterionic complex can then undergo spontaneous proton migration, analogous to that discussed for $\mathrm{S}-\mathrm{S}$ bond cleavage in Pathway 2, to generate the final $\mathrm{c}$ and $\mathrm{z}$ fragments.

We should also mention that, very recently, Syrstad and Turecek ${ }^{15}$ proposed that electrons could directly attach to amide groups when one or more positive charges are nearby. They also suggested a mechanism very similar to that shown in Scheme 3 but with the proton transferring to the carbonyl oxygen in concert with cleavage of the $\mathrm{N}-\mathrm{C}_{\alpha}$ bond. Also, quite recently, Bakken et al. ${ }^{16}$ used ab initio quantum chemistry and classical molecular dynamics simulations to examine several reaction pathways that could arise in peptide fragmentation of $\mathrm{N}-\mathrm{C}_{\alpha}$ bonds.

Therefore, it seems that a plausible case can be made that Coulomb-assisted direct electron attachment might occur for cleaving $\mathrm{S}-\mathrm{S}$ and $\mathrm{N}-\mathrm{C}_{\alpha}$ bonds. It is important to note that the Coulomb-assisted direct attachment mechanism is most likely to be operative for the cleavages that occur in ECD and ETD, because these two cleavages involve the two lowest-energy $\left(\mathrm{S}-\mathrm{S} \sigma^{*}\right.$ and $\mathrm{C}=\mathrm{O} \pi^{*}$ ) antibonding orbitals found in most peptides and proteins. To cleave, for example, an $\mathrm{N}-\mathrm{C}_{\alpha}$ bond by directly capturing an electron into the $\sigma^{*}$-orbital of this bond would require much greater Coulomb assistance, because the $\mathrm{N}-\mathrm{C}_{\alpha}$ bond is very strong; it is the relatively weak $\mathrm{S}-\mathrm{S} \sigma$ and $\mathrm{C}=\mathrm{O} \pi$ bonds that have the low-lying antibonding orbitals that are more likely involved in Coulomb-assisted ECD or ETD.

This brings us to the primary focus of the present effort. We aim to probe the relative cross-sections (or probabilities) for attaching an electron either to the positive site or to the $\mathrm{S}-\mathrm{S}$ $\sigma^{*}$ orbital of the same model compound as we used in ref $10 \mathrm{~b}$, Me-SS $-\mathrm{CH}_{2}-\mathrm{CH}_{2}-\mathrm{NH}_{3}{ }^{+}$. The observations we make will also shed light on the relative attachment rates for Coulomb-stabilized $\mathrm{C}=\mathrm{O} \pi^{*}$ orbitals. By providing a framework in which to understand what governs the propensities for electron attachment to the positive and Coulomb-stabilized bond sites, we hope to make progress toward unraveling the full story behind the mechanism(s) by which the ECD and ETD reactions occur.

\section{Methods}

Although we are attempting to gain insight into the electron attachment event in both the ECD and ETD processes, let us begin by discussing how we model ETD. We make this choice because ETD involves collisions between two molecular ions, both of whose motions one can hope to model using classical dynamics, whereas in ECD, one of the colliding species is an electron that should be treated in a quantum manner.

In the molecular dynamics (MD) calculations relating to ETD, the starting structure of our simulations was taken to be the $\mathrm{MeSSCH}_{2} \mathrm{CH}_{2} \mathrm{NH}_{3}{ }^{+}$cation at its equilibrium geometry with a $\mathrm{CH}_{3}{ }^{-}$anion $50 \AA$ away. We chose to use this anion because it has a relatively small electron binding energy (and, thus, results from it may also be relevant to ECD, which might be viewed as involving the transfer of an electron from a species with zero binding energy) and because its small "size" allows us to accurately monitor, during the classical trajectories, the distance from the sites from which the electron is transferred and the site(s) to which it is attached. The anions used in the ETD experiments of ref 2 had much larger structures (e.g., of the size of anthracene). We chose not to use one of these species in our initial investigation because we believe steric factors arising in these larger species could considerably alter the rates of electron transfer, and we wanted to focus this study on the intrinsic rates of such processes. For all of these reasons, we settled on using the $\mathrm{H}_{3} \mathrm{C}^{-}$anion as our transfer agent.

The impact parameter and orientation of the anion, relative to the cation, were sampled by placing the anion at many positions on a grid $30 \AA$ long and $20 \AA$ wide above the $\mathrm{N}$ atom of the cation. We imparted zero initial kinetic energy to the relative motions of the anion and cation, to simulate the type of low-kinetic-energy conditions used in ETD; of course, the Coulomb attractions between the two ions causes them to accelerate toward each other and, thus, gain kinetic energy.

The MD simulations were performed using the SANDER module of the Amber 7.0 program with the parm99 force field. ${ }^{17}$ The HF/6-31G/RESP methodology ${ }^{18}$ was used to derive charges for the system studied here. Simulations were performed in vacuo at a constant total energy, and data for each run were collected every 4 steps (i.e., every 0.04 ps).

In each classical trajectory, we monitored the distances between the $\mathrm{C}$ atom of the methyl anion and both the $\mathrm{N}$ atom of the $\mathrm{MeSSCH}_{2} \mathrm{CH}_{2} \mathrm{NH}_{3}{ }^{+}$cation $\left(R_{\mathrm{N}}\right)$ and the midpoint of the $\mathrm{S}-\mathrm{S}$ bond in this cation $\left(R_{\mathrm{SS}}\right)$. The simulations were terminated after the $R_{\mathrm{N}}$ and $R_{\mathrm{SS}}$ values were less than the estimated values of the two crossing distances $\left(R_{\mathrm{N}} \approx 3.5 \AA\right.$ and $R_{\mathrm{SS}} \approx 13 \AA$ ). The coordinates of the atoms in the cation-anion collision complex were then used to perform single-point energy calculations at the unrestricted Hartree-Fock (UHF) level of theory, ${ }^{19}$ using aug-cc-pVDZ basis sets. ${ }^{20}$ To generate the $\mathrm{MeSSCH}_{2} \mathrm{CH}_{2} \mathrm{NH}_{3}{ }^{+} \cdot . \mathrm{CH}_{3}{ }^{-}$and $\mathrm{MeSSCH}_{2} \mathrm{CH}_{2} \mathrm{NH}_{3} \cdots \mathrm{CH}_{3}$ (with the electron either residing in the $\mathrm{S}-\mathrm{S} \sigma^{*}$-orbital or in the $-\mathrm{NH}_{3}{ }^{+}$Rydberg orbital) energies as functions of $R_{\mathrm{SS}}$ or $R_{\mathrm{N}}$ (shown later in Figures 6 and 7),we performed such UHF calculations at a range of $R$-values but with all other geometrical degrees of freedom frozen at the values they have in the terminated MD simulation structures.

The $\mathrm{MeSSCH}_{2} \mathrm{CH}_{2} \mathrm{NH}_{3} \cdots \mathrm{CH}_{3}$ calculations are especially problematic at geometries where the $\mathrm{MeSSCH}_{2} \mathrm{CH}_{2} \mathrm{NH}_{3} \cdots \mathrm{CH}_{3}$ energy lies above that of the $\mathrm{MeSSCH}_{2} \mathrm{CH}_{2} \mathrm{NH}_{3}{ }^{+} \cdot \mathrm{CH}_{3}{ }^{-}$ionpair state. To overcome these problems, we use a device that we have found (see refs 10) to be useful in many earlier studies of such electronically metastable states. Specifically, we artificially increased the nuclear charges of the atoms ( $\mathrm{S}$ and $\mathrm{S}$ for the $\mathrm{S}-\mathrm{S} \sigma^{*}$ state or $\mathrm{N}$ for the Rydberg state) involved in accepting the transferred electron by an amount $\delta q$ (i.e, we made the nuclear charges of $\mathrm{S}$ equal to $16 \times \delta q$ and that of $\mathrm{N}$ equal to $7 \times \delta q$ ) and performed the $\mathrm{MeSSCH}_{2} \mathrm{CH}_{2} \mathrm{NH}_{3} \cdots \mathrm{CH}_{3}$ and $\mathrm{MeSSCH}_{2} \mathrm{CH}_{2} \mathrm{NH}_{3}{ }^{+} \ldots{ }^{-} \mathrm{CH}_{3}$ calculations. These calculations were performed for several values of $\delta q(\delta q=0.1,0.2, \ldots$, $0.5)$, and the energy differences between the two species were then extrapolated to $\delta q=0$ to obtain the true energy of $\mathrm{MeSSCH}_{2} \mathrm{CH}_{2} \mathrm{NH}_{3} \cdots \mathrm{CH}_{3}$, relative to that of $\mathrm{MeSSCH}_{2}-$ $\mathrm{CH}_{2} \mathrm{NH}_{3}{ }^{+} . . .-\mathrm{CH}_{3}$. All of our calculations were performed using the Gaussian 03 suite $^{21}$ of codes.

\section{Comparison of the Two Competing Attachment Sites}

The first issue to address is why one might not expect attachment to any positive site such as $-\mathrm{NH}_{3}{ }^{+}$to overwhelm attachment to an $\mathrm{S}-\mathrm{S} \sigma^{*}$-orbital (or a $\mathrm{C}=\mathrm{O} \pi^{*}$-orbital), given that the negatively charged electron certainly will be strongly attracted to the former site. In this discussion, we will include what happens in ETD processes, so we also need to address why electron transfer to an $\mathrm{S}-\mathrm{S} \sigma^{*}$-orbital or a $\mathrm{C}=\mathrm{O} \pi^{*}$-orbital might be competitive with transfer to a positive site such as $-\mathrm{NH}_{3}{ }^{+}$, even though the Coulomb forces will cause any anion used in ETD to be preferentially attracted to the positive charge. 


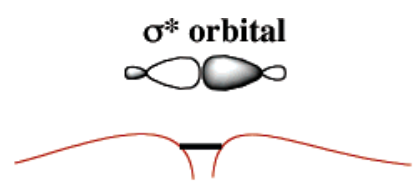

SS bond-site potential in absence of positive charges gives metastable SS $\sigma^{*}$ state

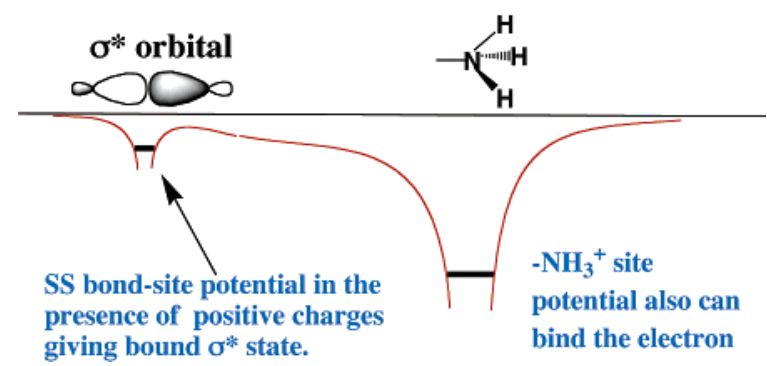

Figure 4. Qualitative depictions of attractive potentials occurring in the model $\mathrm{MeSSCH}_{2} \mathrm{CH}_{2} \mathrm{NH}_{3}{ }^{+}$species. The bold line shows a metastable (top) or bound (bottom) state for an electron. (See text for details.)

A. The Bond-site and Rydberg-site Attractive Potentials. In Figure 4, we offer what we think is a qualitatively useful depiction of the potential experienced by an electron (free in ECD or bound to an anion $\mathrm{A}^{-}$in ETD) approaching a molecule such as Me-SS $-\mathrm{CH}_{2}-\mathrm{CH}_{2}-\mathrm{NH}_{3}{ }^{+}$containing two sites of attraction. In the top of Figure 4, we show the potential that would result from the $\mathrm{S}-\mathrm{S} \sigma^{*}$-site if no charge were present on the $-\mathrm{NH}_{3}{ }^{+}$group; this is meant to show a locally attractive potential that is not deep enough to bind an electron, which is consistent with accessing the $\mathrm{S}-\mathrm{S} \sigma^{*}$-orbital, being $0.9 \mathrm{eV}$ endothermic. $^{22}$ The bottom part of Figure 4 is intended to show a potential near the $\mathrm{S}-\mathrm{S} \sigma^{*}$-orbital that can bind an electron by $2.0 \mathrm{eV}$ and a deeper potential near the $-\mathrm{NH}_{3}{ }^{+}$site that can bind an electron by ca. $4 \mathrm{eV}$.

We want to emphasize that, based on the ideas put forth in Figure 4 , bonds that are very close to any positively charged site may have their antibonding $\left(\sigma^{*}\right.$ or $\left.\pi^{*}\right)$ orbitals so drastically altered by the Coulomb potential of the nearby positive site that they make the binding of an electron to such orbitals impossible. A possible example of such a situation may be offered in a recent study of dissociative recombination ${ }^{23}$ performed on protonated $\mathrm{MeS}-\mathrm{SMe}$ and on $N$-methylacetamide. In the former, the protonation site is at one of the $\mathrm{S}$ atoms and in the latter, it is on the amine $\mathrm{N}$ atom. In this work, it was found that $\mathrm{H}$-atom loss was the dominant channel $(82 \%)$ for protonated $\mathrm{N}$-methylacetamide and $\mathrm{C}-\mathrm{S}$ bond cleavage was the major channel $(62.5 \%)$ for MeSSMe (although $\mathrm{S}-\mathrm{S}$ cleavage as well as the formation of $\mathrm{Me}+\mathrm{S}+\mathrm{SMe}$ accounted for $32 \%$ of the fragments). However, in our opinion, both of these test molecules are not good candidates for the type of Coulombassisted bond-attachment process that we have been studying. We believe the positive charges are too close to merely Coulomb-stabilize antibonding orbitals, so one observes what is characteristic of dissociative recombination: cleavage of bonds immediately surrounding the positively charged sites. We would like to see experiments such as those described in ref 23 conducted on our $\mathrm{MeSSCH}_{2} \mathrm{CH}_{2} \mathrm{NH}_{3}{ }^{+}$ion to determine the branching ratio for $\mathrm{S}-\mathrm{S}$ and $\mathrm{N}-\mathrm{H}$ bond cleavage, for example.

B. Expected Rates of Resonant Electron Transfer. The interaction of an electron with a positive ion is most rigorously treated within the framework of quantum scattering theory, where the wave nature of the electron can be accommodated. Such an approach is presently beyond our capabilities for molecular cations of the complexity treated here, so we must resort to another approach to address the essential question of whether the electron will more likely bind to the Rydberg or the $\mathrm{S}-\mathrm{S} \sigma^{*}$ (or $\mathrm{C}=\mathrm{O} \pi^{*}$ ) site. Our approach is to first address the ETD case and to then attempt to extract from its lessons, as well as from considerations of earlier workers on electroncation and electron-molecule capture processes, information that might apply to ECD.

1. The Electron Transfer Dissociation Case. The ETD experiment involves collisions between a peptide or protein cation and an atomic or molecular anion. The relative translational motion of these two fragments can be treated reasonably well using classical dynamics methods, such as those we have utilized in the present work. Our approach to estimating the relative probabilities for transferring an electron from the valence orbital of $\mathrm{A}^{-}$to either the Rydberg-site orbital or the $\mathrm{S}-\mathrm{S} \sigma^{*}$ site (or the $\mathrm{C}=\mathrm{O} \pi^{*}$ site) has been to conduct classical trajectory simulations in which the following conditions are valid:

(1) The $\mathrm{MeSSCH}_{2} \mathrm{CH}_{2} \mathrm{NH}_{3}{ }^{+}$begins at its equilibrium geometry; ${ }^{24}$

(2) The anion (we have chosen to use $\mathrm{CH}_{3}{ }^{-}$because it binds the electron weakly (ca. $0.1 \mathrm{eV}$ in reality but $0.66 \mathrm{eV}$ using the basis set and theoretical method that we employed here)) has a relatively large orbital that can effectively overlap with either the Rydberg or $\mathrm{S}-\mathrm{S} \sigma^{*_{-}}$( or $\mathrm{C}=\mathrm{O} \pi^{*-}$ ) orbitals. Its weak binding may also allow us to draw conclusions pertinent to the ECD case, because a very weakly bound electron in ETD may behave similar to a free electron in ECD;

(3) The anion-cation distance is initially very large (we use a value of $50 \AA$ ) and there is zero initial inter-ion kinetic energy (see ref 24);

(4) A large range of impact parameters and orientations of the $\mathrm{MeSSCH}_{2} \mathrm{CH}_{2} \mathrm{NH}_{3}{ }^{+}$are used.

In each such trajectory, we monitor the distances between the $\mathrm{C}$ atom of the methyl anion (the center of negative charge) and both the $\mathrm{N}$ atom of the $\mathrm{MeSSCH}_{2} \mathrm{CH}_{2} \mathrm{NH}_{3}{ }^{+}$cation $\left(R_{\mathrm{N}}\right)$ and the midpoint of the $\mathrm{S}-\mathrm{S}$ bond $\left(R_{\mathrm{SS}}\right)$ in this cation. These distances have important roles in our simulations of electron transfer, because they govern the coupling between the $\mathrm{CH}_{3}{ }^{-}$ orbital from which the electron leaves and the $\mathrm{MeSSCH}_{2} \mathrm{CH}_{2-}$ $\mathrm{NH}_{3}{ }^{+}$cation's Rydberg and $\mathrm{S}-\mathrm{S} \sigma^{*}$-orbitals into which the electron moves.

For each trajectory, we need a way to estimate the probability that an electron-transfer event will occur and to which site (i.e., Rydberg or $\mathrm{S}-\mathrm{S}$ ) it will happen. In Figure 5, we show qualitative plots of potential energies for three electronic states of an ETD system in which $\mathrm{MeSSCH} \mathrm{CH}_{2} \mathrm{NH}_{3}{ }^{+}$cations undergo collisions with a molecular anion we call $\mathrm{A}^{-}\left(\mathrm{CH}_{3}{ }^{-}\right.$in our actual simulations). Of course, in our trajectory simulations, actual interfragment potential energies are computed; however, Figure 5 helps to explain the essence of how we extract electron-transfer probabilities.

The three different electronic states whose potentials are depicted in Figure 5, as functions of the distance $R_{\mathrm{N}}$ between the $\mathrm{C}$ atom of $\mathrm{CH}_{3}{ }^{-}$and the $\mathrm{N}$ atom are as follows:

(1) The $\mathrm{MeSSCH}_{2} \mathrm{CH}_{2} \mathrm{NH}_{3}{ }^{+}+\mathrm{A}^{-}$ion-pair state whose potential displays a characteristic Coulomb shape $\left(-\mathrm{e}^{2} / \mathrm{R}=\right.$ $-14.4 \mathrm{eV} / R_{\mathrm{N}}$, if we express $R_{\mathrm{N}}$ in units of $\AA$ ) at inter-ion distances where repulsive potentials (e.g., from inner-region electrons and nuclei) have not yet arisen. The asymptote of this state forms our reference point (i.e., zero) of the energies indicated for all the curves shown.

(2) The $\mathrm{MeSSCH}_{2} \mathrm{CH}_{2} \mathrm{NH}_{3}+\mathrm{A}$ state in which the "extra" electron has transferred from $\mathrm{A}^{-}$to the Coulomb-stabilized $\mathrm{S}-\mathrm{S}$ 


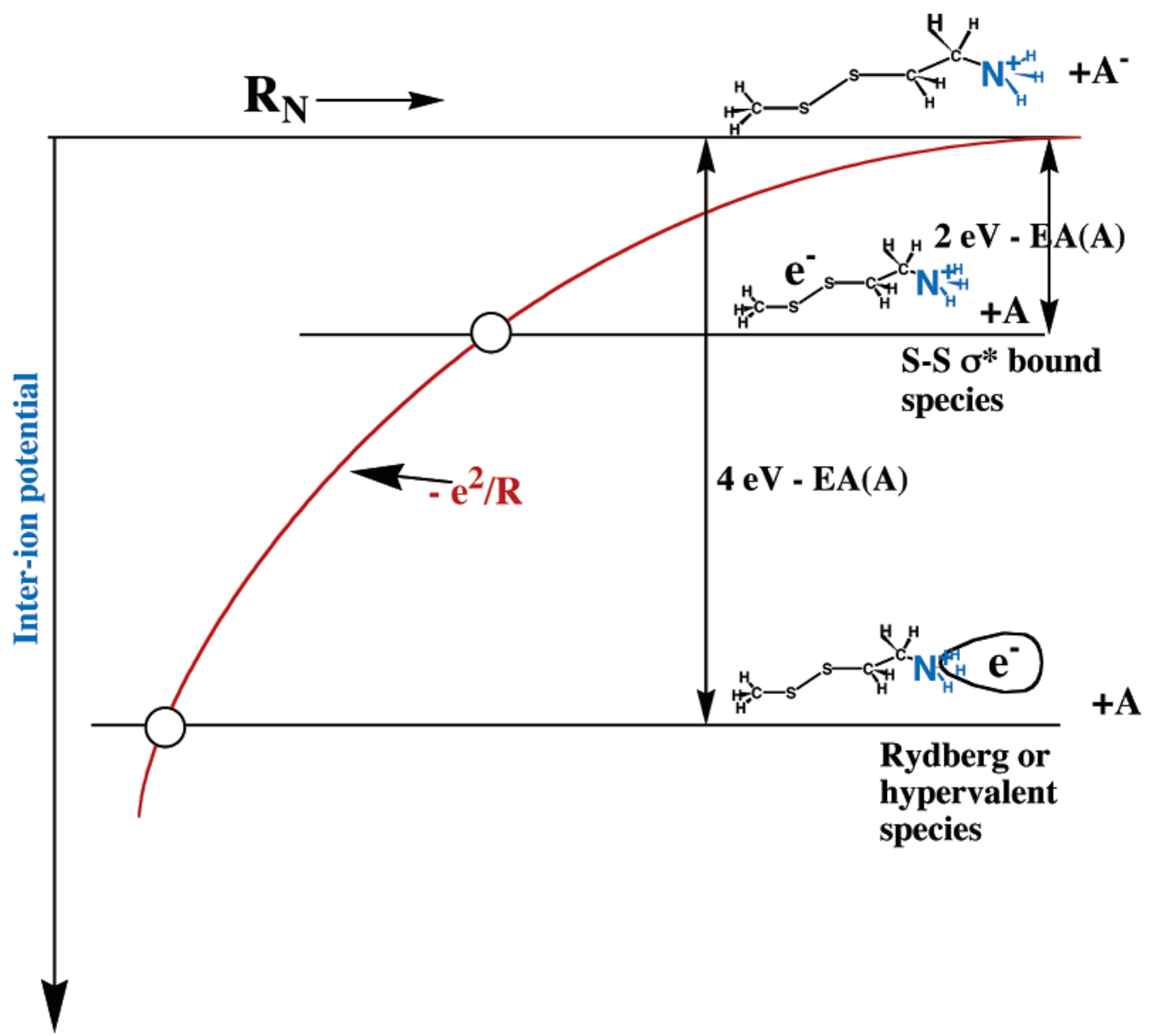

Figure 5. Potential energy of interaction between the $\mathrm{MeSSCH}_{2} \mathrm{CH}_{2} \mathrm{NH}_{3}{ }^{+}$cation and the anion $\mathrm{A}^{-}$, as well as potentials for the two chargeexchanged species. (See text for details.)

$\sigma^{*}$-orbital of $\mathrm{MeSSCH}_{2} \mathrm{CH}_{2} \mathrm{NH}_{3}{ }^{+}$. Asymptotically, this state lies below the separated-ion state by $2.0 \mathrm{eV}$ (the Coulomb-stabilized electron binding energy of the $\mathrm{S}-\mathrm{S} \sigma^{*}$-orbital) minus the electron affinity of A, which we call $E A(\mathrm{~A})$ (e.g., $0.66 \mathrm{eV}$ for our $\mathrm{CH}_{3}{ }^{-}$).

(3) The $\mathrm{MeSSCH}_{2} \mathrm{CH}_{2} \mathrm{NH}_{3}+\mathrm{A}$ state in which the "extra" electron has transferred from $\mathrm{A}^{-}$to the $-\mathrm{NH}_{3}{ }^{+}$centered Rydberg orbital of $\mathrm{MeSSCH}_{2} \mathrm{CH}_{2} \mathrm{NH}_{3}{ }^{+}$. Asymptotically, this state lies below the separated-ion state by $4 \mathrm{eV}$ (the binding energy of the Rydberg state) minus EA(A).

Let us now consider what can happen in a typical ETD collision between one $\mathrm{MeSSCH}_{2} \mathrm{CH}_{2} \mathrm{NH}_{3}{ }^{+}$cation and one $\mathrm{A}^{-}$ anion that encounter each other with very low initial relative kinetic energy (as characteristic of ETD). Their attractive Coulomb potential will cause them to be accelerated toward each other (with the $-\mathrm{NH}_{3}{ }^{+}$site of the cation moving toward $\mathrm{A}^{-}$). As the ions reach the first "crossing" geometry (denoted by the upper circle in Figure 5), their relative kinetic energy will be $2.0 \mathrm{eV}-E A(\mathrm{~A})$, from which we can evaluate their relative velocity $v_{1}=[2(2.0 \mathrm{eV}-E A(\mathrm{~A})) / \mu]^{1 / 2}$, in terms of the reduced mass $(\mu)$ of the two ions. At this first crossing point, a resonant electron transfer from the orbital of $\mathrm{A}^{-}$initially holding the electron and the $\mathrm{S}-\mathrm{S} \sigma^{*}$ orbital is possible. At the second crossing point, the relative velocity is $v_{2}=[2(4 \mathrm{eV}-E A(\mathrm{~A})) /$ $\mu]^{1 / 2}$ and resonant electron transfer to the $-\mathrm{NH}_{3}{ }^{+}$Rydberg orbital can occur.

The probability $P$ of such resonant transfer processes can be expressed in terms of Landau-Zener-Stueckelberg (LZS) theory ${ }^{25}$ as follows:

$$
\begin{gathered}
P_{\sigma^{*}}=1-\exp \left[-2 \pi \mathscr{H}_{1,2}^{2} /\left(\hbar v_{1}\left|\Delta F_{1,2}\right|\right)\right] \\
P_{\text {Rydberg }}=1-\exp \left[-2 \pi \mathscr{H}_{1,3}^{2} /\left(\hbar v_{2}\left|\Delta F_{1,3}\right|\right)\right]
\end{gathered}
$$

where $v_{1}$ and $v_{2}$ are the velocities introduced previously, $\Delta F_{1, J}$ is the difference is the slopes of the two potential surfaces at the crossing point, and $\mathscr{H}_{1, J}$ represents the electronic Hamiltonian matrix elements connecting the pairs of electronic configurations whose curves cross. Assuming that the two curves in which either state of the neutral $\mathrm{MeSSCH}_{2} \mathrm{CH}_{2} \mathrm{NH}_{3}$ interacts with the neutral $\mathrm{A}$ are essentially flat at large interfragment distances, and that the curve describing the $\mathrm{MeSSCH}_{2} \mathrm{CH}_{2} \mathrm{NH}_{3}{ }^{+}+\mathrm{A}^{-}$ interaction can be approximated as $-\mathrm{e}^{2} / R$, we can solve for the two crossing distances (if the distances used are given in units of $\AA$ and the energies appear in units of $\mathrm{eV}$ ):

$$
\begin{aligned}
R_{1} & =\frac{14.4}{2.0-E A(\mathrm{~A})} \\
R_{2} & =\frac{14.4}{4-E A(\mathrm{~A})}
\end{aligned}
$$

as well as for the slope differences $\Delta F$ (given in units of $\mathrm{eV} / \AA$ ) at the two distances $\Delta F_{1,2}$ and $\Delta F_{1,3}$ :

$$
\begin{aligned}
& \Delta F_{1,2}=\frac{14.4}{R_{1}^{2}} \\
& \Delta F_{1,3}=\frac{14.4}{R_{2}^{2}}
\end{aligned}
$$


For the $\mathrm{CH}_{3}{ }^{-}$anion that we use for $\mathrm{A}^{-}$, the value of $E A$ is ca. $0.66 \mathrm{eV}$, so $R_{1}=10.75 \AA, R_{2}=4.31 \AA$. $\Delta F_{1,2}=0.125 \mathrm{eV} / \AA$ $=2.42 \times 10^{-3}$ hartrees $/$ bohr, and $\Delta F_{1,3}=0.775 \mathrm{eV} / \AA=1.51$ $\times 10^{-2}$ hartrees/bohr. The velocities at the two crossing points can also be obtained for this specific case, and we find $v_{1}=$ $1.9 \times 10^{-3}$ bohr/au and $v_{2}=3.0 \times 10^{-3}$ bohr/au. Of course, these values are only estimates that can be used to gain qualitative predictions of the transfer rates. However, as we show later, the predictions achieved within this model are in rather good agreement with those obtained by running classical trajectories. We should also note that LZS theory has been successfully applied ${ }^{26}$ to a problem that is very similar to that studied here: the calculation of transition probabilities for cation-anion pairs being formed when species in Rydberg and valence states collide. It is also used ${ }^{27}$ to interpret the rates as which electrons are transferred from Rydberg states of atoms to molecules with large dipole moments to form dipole-bound anions.

The only quantities one still needs to obtain to permit an estimate of the rates of hopping from the (diabatic) $\mathrm{MeSSCH}_{2}-$ $\mathrm{CH}_{2} \mathrm{NH}_{3}{ }^{+}+\mathrm{A}^{-}$surface to either of the two (diabatic) chargeexchanged surfaces are the two Hamiltonian matrix elements $\mathscr{H}_{1,2}$ (for the $\mathrm{S}-\mathrm{S} \sigma^{*}$ surface) and $\mathscr{H}_{1,3}$ (for the Rydberg-orbital surface). These coupling matrix elements, which result in the adiabatic surfaces, are dependent on the overlaps between the orbital of $\mathrm{CH}_{3}{ }^{-}$that initially holds the electron and the $\mathrm{S}-\mathrm{S}$ $\sigma^{*}$-orbitals and Rydberg orbitals into which the electron is transferred. To obtain these matrix elements for use in calculating electron-transfer rates, we performed several electronic structure calculations in the neighborhoods of the two crossings. Within the first neighborhood, we calculated the energies of two different electronic states: that with an orbital occupation corresponding to the $\mathrm{MeSSCH}_{2} \mathrm{CH}_{2} \mathrm{NH}_{3}{ }^{+}+\mathrm{A}^{-}$ion pair, and another with an orbital occupancy corresponding to $\mathrm{MeSSCH}_{2}-$ $\mathrm{CH}_{2} \mathrm{NH}_{3}+\mathrm{A}$ with the electron residing in the $\mathrm{S}-\mathrm{S} \sigma^{*}$-orbital. Within the second neighborhood, we also calculated the energies of two different electronic states: that with an orbital occupation corresponding to the $\mathrm{MeSSCH}_{2} \mathrm{CH}_{2} \mathrm{NH}_{3}{ }^{+}+\mathrm{A}^{-}$ion pair, and another with an orbital occupancy corresponding to $\mathrm{MeSSCH}_{2-}$ $\mathrm{CH}_{2} \mathrm{NH}_{3}+$ A with the electron residing in the $-\mathrm{NH}_{3}{ }^{+}$Rydberg orbital. By plotting these pairs of energies throughout the crossing regions, we extract the magnitude of the coupling Hamiltonian matrix element from the smallest energy splitting ${ }^{28}$ between the energies of the two adiabatic states. In Figures 6 and 7, we show two such avoided-crossing plots; one relates to the $\mathrm{S}-\mathrm{S} \sigma^{*}$ state and one to the $-\mathrm{NH}_{3}{ }^{+}$Rydberg state.

Note that the distance at which the avoided crossing occurs for the Rydberg case ( $3.65 \AA$ ) of Figure 7 is not exactly the distance $(4.31 \AA)$ predicted by the simple Coulomb model introduced previously. This is because the $\mathrm{MeSSCH}_{2} \mathrm{CH}_{2} \mathrm{NH}_{3}{ }^{+}$ $+\mathrm{A}^{-}$potential is not purely Coulombic and the $\mathrm{MeSSCH}_{2}-$ $\mathrm{CH}_{2} \mathrm{NH}_{3}+$ A potential is not entirely flat. The distance at which the avoided crossing occurs for the $\sigma^{*}$ case $(13.05 \AA)$ of Figure 6 seems to be much larger than that $(10.75 \AA)$ predicted in the Coulomb potential model. However, what the Coulomb model predicts is the critical $\mathrm{H}_{3} \mathrm{C}^{-}$to $\mathrm{N}$ distance $\left(R_{\mathrm{N}}\right)$, whereas in Figure 6 , it is the $\mathrm{H}_{3} \mathrm{C}^{-}$to $\mathrm{S}-\mathrm{S}$ bond midpoint distance $\left(R_{\mathrm{SS}}\right)$ that appears on the horizontal axis. Thus, to compare the prediction of the Coulomb model to the ab initio computed crossing point, we must relate $R_{\mathrm{N}}$ and $R_{\mathrm{SS}}$ for this $\sigma^{*}$ crossing case. We noticed by examining many dynamical trajectories that, regardless of where (i.e., impact parameter and orientation) the $\mathrm{CH}_{3}{ }^{-}$ion initiates its collision, the attractive Coulomb forces between it and the nitrogen center of $\mathrm{MeSSCH}_{2} \mathrm{CH}_{2} \mathrm{NH}_{3}{ }^{+}$

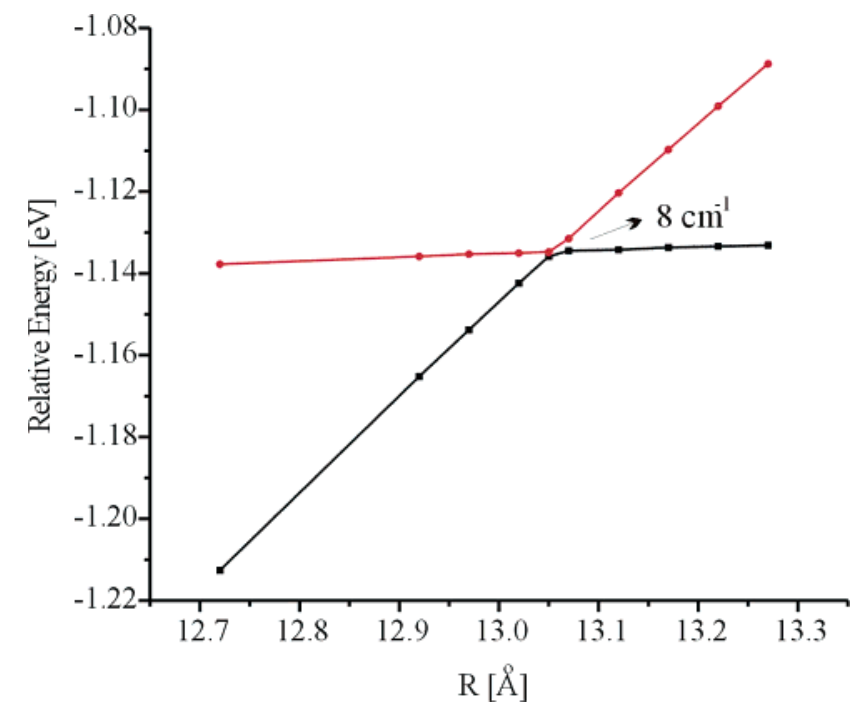

Figure 6. Energies of the $\mathrm{MeSSCH}_{2} \mathrm{CH}_{2} \mathrm{NH}_{3}{ }^{+}+\mathrm{CH}_{3}{ }^{-}$(higher curve at large $R$ and lower curve at small $R$ ) and $\mathrm{S}-\mathrm{S} \sigma^{*}$ (lower at large $R$ and higher at small $R$ ) $\mathrm{MeSSCH}_{2} \mathrm{CH}_{2} \mathrm{NH}_{3}+\mathrm{CH}_{3}$ surfaces, each as a function of the distance from the methyl $\mathrm{C}$ atom to the $\mathrm{S}-\mathrm{S}$ midpoint.

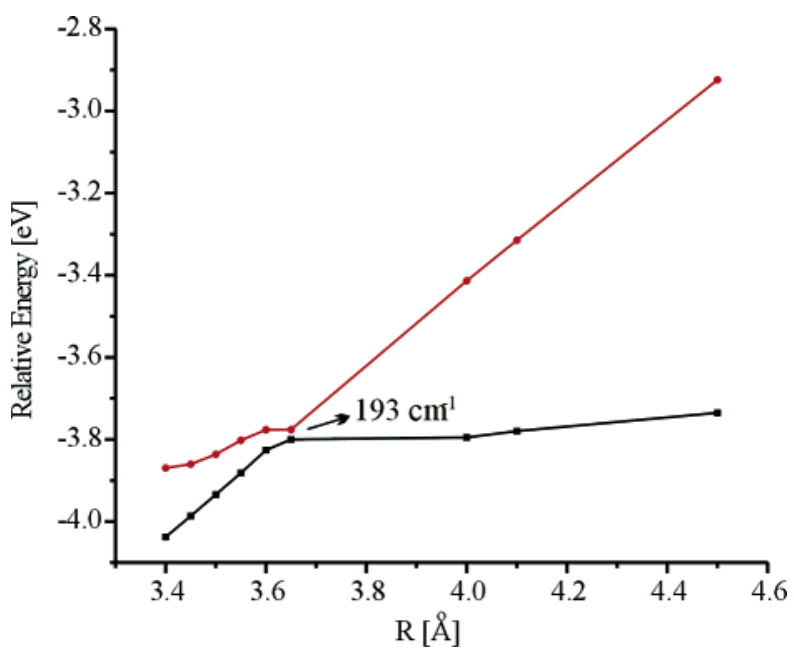

Figure 7. Energies of the $\mathrm{MeSSCH}_{2} \mathrm{CH}_{2} \mathrm{NH}_{3}{ }^{+}+\mathrm{CH}_{3}{ }^{-}$(higher curve at large $R$ and lower curve at small $R$ ) and $-\mathrm{NH}_{3}{ }^{+}$Rydberg (lower at large $R$ and higher at small $R$ ) $\mathrm{MeSSCH}_{2} \mathrm{CH}_{2} \mathrm{NH}_{3}+\mathrm{CH}_{3}$ surfaces, each as a function of the distance from the methyl $\mathrm{C}$ atom to the $\mathrm{N}$ atom.

generates an almost collinear arrangement of the $\mathrm{S}-\mathrm{S}, \mathrm{N}$, and $\mathrm{CH}_{3}{ }^{-}$units as the trajectory enters the curve-crossing regions. Representative such geometrical configurations for the $\mathrm{S}-\mathrm{S} \sigma^{*}$ and $-\mathrm{NH}_{3}{ }^{+}$Rydberg curve crossing regions are shown in Figure 8.

Knowing that all trajectories access such geometries near the crossings allows us to relate $R_{\mathrm{N}}$ to $R_{\mathrm{SS}}$, given that the distance from the midpoint of the $\mathrm{S}-\mathrm{S}$ bond and the $\mathrm{N}$ atom is $4.8 \AA$. Thus, the $R_{\mathrm{SS}}=13.05 \AA$ value shown in Figure 6 corresponds to a value of $R_{\mathrm{N}}=8.25 \AA$, which is shorter than the $R_{\mathrm{N}}=$ $10.75 \AA$ value predicted using the simple Coulomb formula (again because the potential curves are not entirely Coulombic and flat as assumed).

One other important point to make involves how trajectories move through the two crossing points. From Figure 5 and keeping in mind the near-collinear $\mathrm{SS}-\mathrm{N}-\mathrm{CH}_{3}$ geometries that characterize essentially all trajectories at the critical distances, it should be clear that the $\mathrm{S}-\mathrm{S} \sigma^{*}$ crossing will always be accessed before the $-\mathrm{NH}_{3}{ }^{+}$Rydberg crossing, as illustrated in Figure 9. 

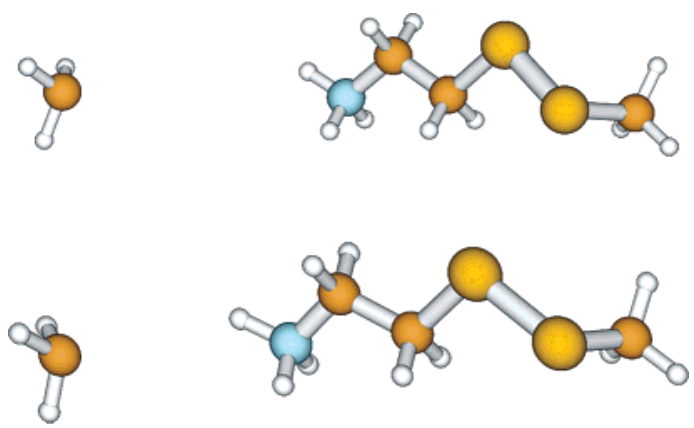

Figure 8. Representative geometries realized when $\mathrm{CH}_{3}{ }^{-}$(left) collides with $\mathrm{MeSSCH}_{2} \mathrm{CH}_{2} \mathrm{NH}_{3}{ }^{+}$and reaches the $\mathrm{S}-\mathrm{S} \sigma^{*}$ (top) and $-\mathrm{NH}_{3}{ }^{+}$ Rydberg (bottom) curve crossings, clearly showing the characteristic near-collinear $\mathrm{C}-\mathrm{N}-\mathrm{SS}$ orientation.

Thus, all trajectories will have a chance to undergo an electron transfer to the weaker bond-attached ( $\sigma^{*}$, in our case) site before realizing a chance to transfer to the stronger + -attached (Rydberg, in our case) site. This somewhat counterintuitive observation suggests that Coulomb-assisted bond attachment may indeed have a chance to compete against the stronger positively charged site.

Now, let us return to estimating the electron-transfer rates, which is the primary focus of this work. From the closest approach between pairs of the energy-versus-distance plots shown in Figures 6 and 7, we can evaluate the magnitudes of the $\mathscr{H}_{1,2}$ and $\mathscr{M}_{1,3}$ matrix elements:

$$
\begin{gathered}
\mathscr{H}_{1,2}=4 \mathrm{~cm}^{-1} \\
\mathscr{T}_{1,3}=96 \mathrm{~cm}^{-1}
\end{gathered}
$$

Combining these coupling matrix elements with the force and velocity estimates quoted previously, we can evaluate the quantity entering into the exponential factor in eq 1 :

$$
\begin{aligned}
& \frac{2 \pi \mathscr{H}_{1.2}^{2}}{\hbar v_{1}\left|\Delta F_{1,2}\right|}=4.54 \times 10^{-4} \\
& \frac{2 \pi \mathscr{H}_{1.3}^{2}}{\hbar v_{2}\left|\Delta F_{1,3}\right|}=267 \times 10^{-4}
\end{aligned}
$$

Because these factors are small fractions, we can approximate the exponentials appearing in eq 1 as $1-\exp (-x) \approx x$ to obtain the probabilities for transferring an electron either to the $\mathrm{S}-\mathrm{S}$ $\sigma^{*}$ site or to the $-\mathrm{NH}_{3}{ }^{+}$Rydberg site in a resonant process:

$$
\begin{gathered}
P_{\sigma^{*}}=4.54 \times 10^{-4} \\
P_{\text {Rydberg }}=267 \times 10^{-4}
\end{gathered}
$$

When we use the actual classical trajectory velocities $\left(v_{1}=2.8\right.$ $\times 10^{-3} \mathrm{bohr} / \mathrm{au}$ and $\left.v_{2}=6.2 \times 10^{-3} \mathrm{bohr} / \mathrm{au}\right)$ and potential slope differences $\left(\Delta F_{1,2}=8.7 \times 10^{-4}\right.$ hartree/bohr and $\Delta F_{1,3}$ $=1.0 \times 10^{-2}$ hartree/bohr), we obtain $\mathrm{P}_{\sigma^{*}}=8 \times 10^{-4}$ and $P_{\text {Rydberg }}=182 \times 10^{-4}$, in agreement with the simple Coulomb model's predictions (eqs 6) to within a factor of 2 . To estimate cross sections for these two processes, we can multiply these probabilities by $\pi R_{\mathrm{C}}^{2}$ for the two crossing radii and obtain

$$
\begin{gathered}
\sigma_{\sigma^{*}}=0.16 \AA^{2} \\
\sigma_{\text {Rydberg }}=1.6 \AA^{2}
\end{gathered}
$$

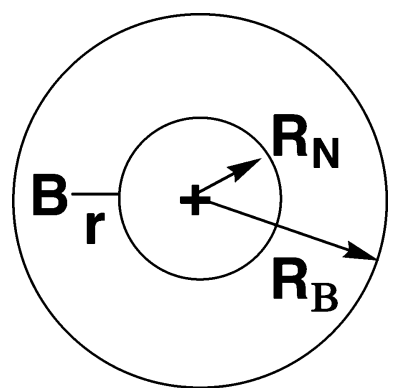

Figure 9. Prototypical bond (B) and cation $(+)$ compound, with B and + separated by a distance $r$. The spheres, of radii $R_{\mathrm{N}}$ and $R_{\mathrm{B}}$, denote the surfaces at which an anion (or electron)-cation Coulombic energy surface will intersect the bond-attached or cation-attached energy surface, respectively.

Therefore, the two cross sections (and, thus, the rate constants) are more similar than are the attachment probabilities.

To refine the accuracy of our determination of the probabilities for transferring electron and cross sections, we subsequently repeated our UHF-level studies (as detailed in Figures 6 and 7) at the second-order Møller-Plesset (MP2) correlated level of theory. We found that the magnitudes of the matrix elements are

$$
\begin{aligned}
\mathscr{H}_{1,2} & =1 \mathrm{~cm}^{-1} \\
\mathscr{H}_{1,3} & =59 \mathrm{~cm}^{-1}
\end{aligned}
$$

Inserting these new values of matrix elements in eqs 5, we obtain probabilities of $2.84 \times 10^{-5}$ and $100.23 \times 10^{-4}$ for transferring an electron to the $\mathrm{S}-\mathrm{S} \sigma^{*}$ site or the $-\mathrm{NH}_{3}{ }^{+}$Rydberg site, respectively. Therefore, we can approximate the two cross sections as

$$
\sigma_{\sigma^{*}}=0.01 \AA^{2}
$$

and

$$
\sigma_{\text {Rydberg }}=0.58 \AA^{2}
$$

at the MP2 level of theory.

As noted previously, these results are based on approximations to the ion-pair and neutral energy curves and to the resultant velocities and force differences, although they do use $\mathrm{ab}$ initio data for the Hamiltonian couplings. Nevertheless, they suggest the following:

(1) The couplings are weak enough to render the probabilities per collision for hopping either to the $\mathrm{S}-\mathrm{S} \sigma^{*}$ surface or the $-\mathrm{NH}_{3}{ }^{+}$surface small. This implies that the cross sections for bond cleavage via either mechanism should be a small fraction of the collision cross section, as the data of eq 7 show. ${ }^{29}$

(2) Although transfer to the Rydberg surface is more likely than to the $\sigma^{*}$ surface (primarily because of the larger Hamiltonian coupling), the difference in probability is not more than 2 orders of magnitude and the cross-section ratios are even more similar.

Before moving on to discuss the ECD case, let us consider what one might expect if the $\mathrm{CH}_{3}{ }^{-}$anion used in the present simulations were replaced by another anion. To do so, we examine the factors entering into the quantity $2 \pi \mathscr{K}_{1,2}^{2} /\left(\hbar v_{1}\left|\Delta F_{1,2}\right|\right)$ and the crossing radius. If an anion with a larger electron binding energy than $\mathrm{CH}_{3}{ }^{-}$were used:

(1) Both the $\sigma^{*}$ and Rydberg crossing points would be shifted to smaller values of $R$, so both the $v$ and $|\Delta F|$ values would be 
larger but not by orders of magnitude. These trends would have a tendency to decrease the electron-transfer probabilities.

(2) However, both the $\mathscr{H}_{1,2}$ and $\mathscr{H}_{1,3}$ values would be larger (and could be so by considerable amounts), because these coupling matrix elements are dependent on the overlaps of the anion orbital and the $\mathrm{S}-\mathrm{S} \sigma^{*}$-orbital or $-\mathrm{NH}_{3}{ }^{+}$Rydberg orbital. Such overlaps are dependent exponentially on the distance between the two centers where the orbitals are localized, which is why we suggest the matrix elements could be much larger for anions with higher electron binding energies. Moreover, because it is the squares of these coupling elements that appear in the electron-transfer rate expression, these trends would likely have a tendency to dominate those resulting from $v$ and $\Delta F$ and, thus, produce greater transfer rates.

(3) The shift of both crossing points to smaller values would have a tendency to decrease both cross sections.

Of course, the opposite trends would apply if an anion with a smaller binding energy were used. To the extent that ECD can be viewed as ETD with an anion of very low electron binding energy, this would seem to suggest that the transfer probabilities in ECD should be smaller than those in ETD, because the $\mathscr{H}_{1,2}$ and $\mathscr{H}_{1,3}$ matrix elements in ECD would be smaller than those in ETD. However, because ECD will have larger crossing points than ETD, this would have a tendency to increase the cross sections and, thus, the rates.

In the following section, we further discuss the ECD case, but before moving on to that topic, we note that an interesting suggestion results from the aforementioned analysis. In particular, we suggest that if one were to use an anion whose electron binding energy exceeds that of the $\mathrm{S}-\mathrm{S} \sigma^{*}$ site (i.e, 2 $\mathrm{eV}$ for the model cation used in this work, but smaller if a cation with more methylene units (such as $\mathrm{MeSS}\left(\mathrm{CH}_{2}\right)_{4} \mathrm{NH}_{3}{ }^{+}$) were used $^{30}$ ), one could render transfer to the $\sigma^{*}$-site energetically impossible. In this case, one could expect that any $\mathrm{S}-\mathrm{S}$ bond fragmentation must result from electron attachment to the Rydberg site, followed by bond cleavage via the mechanism of Scheme 2. Conducting such ETD experiments would be an excellent test of the validity of the Coulomb-assisted $\mathrm{S}-\mathrm{S} \sigma^{*}$ attachment mechanism that we have suggested.

2. The Electron Capture Dissociation Case. It is not at all clear that the rates of electron transfer to the $\mathrm{S}-\mathrm{S} \sigma^{*}$ (or $\mathrm{C}=\mathrm{O}$ $\left.\pi^{*}\right)$ site and the $-\mathrm{NH}_{3}{ }^{+}$site in ECD experiments can be estimated using analytical expressions (e.g., eq 1) applicable to ETD with the anion binding energy set to zero.

After all, when the electron is electronically bound in an orbital of any stable anion, it is spatially localized (albeit probably over a substantially large orbital, because anions have small electron binding energies) and, thus, its trajectory toward the cation is governed by classical mechanics. In contrast, the free electrons of ECD should be described by spatially delocalized continuum functions and treated by quantum mechanics. Therefore, it is wise to attempt to gain estimates for ECD processes using an independent approach to that detailed previously, which is what we now offer.

The continuum-electron wave function can be characterized by local de Broglie wavelength,

$$
\lambda=\frac{2 \pi \hbar}{\left(2 m_{\mathrm{e}} K E\right)^{1 / 2}}
$$

which is dependent on the kinetic energy $(K E)$ of the electron. In the ECD source, the electron kinetic energy distribution is peaked at very low values (e.g., in the range of tenths of an electron volt). However, as the electrons are accelerated toward the positive site(s) (of our model compound or of a peptide or protein sample), $K E$ increases, so $\lambda$ decreases. At the crossing points (i.e., as in Figure 5 but with $E A(\mathrm{~A})=0$ ), the electron's kinetic energy will equal the binding energy of the $\mathrm{S}-\mathrm{S} \sigma^{*}$ site (first crossing) or that of the $-\mathrm{NH}_{3}{ }^{+}$site (second crossing). Using values of 2 and $4 \mathrm{eV}$, respectively, for these two binding energies, we obtain $\lambda$ values of $8.7 \AA$ (at the $\mathrm{S}-\mathrm{S} \sigma^{*}$ crossing) and $5.8 \AA$ (at the $-\mathrm{NH}_{3}{ }^{+}$crossing). To the extent that waves of these $\lambda$ values overlap with the $\sigma^{*}$-orbitals and Rydberg orbitals, whose radial extents are not that much smaller than these values, the coupling matrix elements $\mathscr{H}_{1,2}$ and $\mathscr{H}_{1,3}$ will be significant. Although the evaluation of Hamiltonian matrix elements between continuum electron wave functions and bound orbitals is beyond our current abilities for systems as complex as we study here, we would expect $\mathscr{H}_{1,2}$ and $\mathscr{H}_{1,3}$ to not differ by more than an order of magnitude for the two cases at hand. We say this because the de Broglie wavelengths are similar (6 $\AA$ and $9 \AA$ ), as are the radial extents of the $\sigma^{*}$-orbitals and Rydberg orbitals. ${ }^{31}$ The primary conclusion of this analysis is that there is no reason to believe that the relative probabilities of transferring to the $\mathrm{S}-\mathrm{S} \sigma^{*}$ site or to the $-\mathrm{NH}_{3}{ }^{+}$Rydberg site will be substantially different in ECD than the aforementioned estimates in ETD suggest. Of course, these conclusions are based on our ability to view the ECD process as being similar to an ETD event whose anion has a vanishingly small electron binding energy.

To base our analysis of ECD on an even broader set of experiences, let us also examine what is known about the cross sections for attaching low-energy electrons to cations and to neutral molecules and consider applying this knowledge to our $\sigma^{*}$ and Rydberg ECD attachments.

Unfortunately, very few absolute cross sections have been determined for electron attachment to cations, and, to the best of our knowledge, this cross section is not known for our model compound. It is known ${ }^{32}$ that the cross section for the attachment of $0.1 \mathrm{eV}$ electrons ${ }^{33}$ to a cation site such as $\mathrm{OH}_{3}{ }^{+}+\mathrm{e}^{-} \rightarrow$ $\mathrm{OH}_{3}$ is on the order of $10^{-14} \mathrm{~cm}^{2}$. It is believed that the process occurs by initial capture into a high Rydberg state of the $\mathrm{OH}_{3}$ radical, followed by radiationless relaxation to lower electronic states. Moreover, the cross section for $\mathrm{SH}_{3}{ }^{+}+\mathrm{e}^{-} \rightarrow \mathrm{SH}_{3}$ is also ca. $10^{-14} \mathrm{~cm}^{2}$, so it seems reasonable to assume that the $-\mathrm{NH}_{3}{ }^{+}+\mathrm{e}^{-} \rightarrow-\mathrm{NH}_{3}$ Rydberg-site attachment cross section is in this same range for electrons in the $0.1 \mathrm{eV}$ energy range that is applicable to ECD.

When considering attachment to the $\sigma^{*}$-orbital, we again face a situation in which the absolute cross section for our compound is not known. Therefore, we must make a reasonable estimate of this cross section as well. The dissociative attachment cross section for attaching to the $\sigma^{*}$-orbital and subsequently cleaving the $\mathrm{C}-\mathrm{Cl} \sigma$-bond in $\mathrm{CHF}_{2} \mathrm{Cl}+\mathrm{e}^{-} \rightarrow \mathrm{Cl}^{-}+\mathrm{CHF}_{2}$ has been determined ${ }^{34}$ to be $2 \times 10^{-19} \mathrm{~cm}^{2}$. However, this value reflects the cross section for electron capture multiplied by the fraction $F$ of nascent $\left(\mathrm{CHF}_{2} \mathrm{Cl}\right)^{-} \sigma^{*}$ anions that survive long enough for their $\mathrm{C}-\mathrm{Cl}$ bond to rupture. This fraction is governed by the rate at which the $\mathrm{C}-\mathrm{Cl}$ bond breaks $\left(k_{\mathrm{diss}}\right)$ (ca. in one-half of a vibrational period, or at a rate of $10^{14} \mathrm{~s}^{-1}$ ) and the rate at which the $\sigma^{*}$ anion undergoes electron autodetachment $\left(k_{\text {detach }}\right)$ (ca. $\left.10^{15} \mathrm{~s}^{-1}\right)$. Therefore, $F=k_{\text {diss }} /\left(k_{\text {diss }}+k_{\text {detach }}\right)$, which is $\sim 10^{-1}$ in the $\mathrm{C}-\mathrm{Cl}$ bond rupture case. This means that the cross section for electron capture is in the $2 \times 10^{-18} \mathrm{~cm}^{2}$ range for $\mathrm{CHF}_{2} \mathrm{Cl}$. Another example of a known cross section for DEA is that for the process shown in Scheme 4 , which is $7 \times 10^{-18}$ $\mathrm{cm}^{2}{ }^{35}$ 


\section{SCHEME 4}

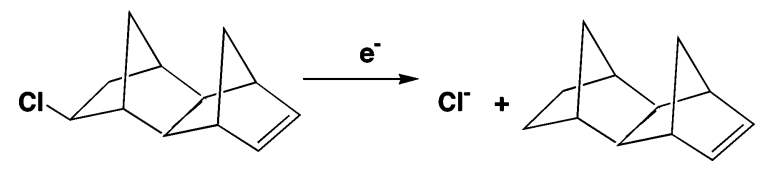

Again, this cross section relates to the attachment (to the olefin $\pi^{*}$-orbital), followed by the cleavage (of the $\mathrm{C}-\mathrm{Cl} \sigma$ bond); therefore, it must be corrected for the fraction $F$ of nascent $\pi^{*}$ anions that survive long enough to break the $\mathrm{C}-\mathrm{Cl}$ bond. This fraction is also in the $10^{-1}$ range; therefore, for Scheme 4 , the cross section for attachment alone is $\sim 7 \times 10^{-17} \mathrm{~cm}^{2}$.

The attachment cross-section data presented previously suggests that attachment to the $\mathrm{S}-\mathrm{S} \sigma^{*}$ site $\left(\sigma \approx 10^{-16}-10^{-17}\right.$ $\mathrm{cm}^{2}$ ) can be expected to be a few orders of magnitude smaller than the attachment to the $-\mathrm{NH}_{3}{ }^{+}$Rydberg site $\left(\sigma \approx 10^{-14}\right.$ $\mathrm{cm}^{2}$ ). Our earlier analysis, based on the ETD case, suggests that the respective cross sections should be ca. $1.6 \times 10^{-17} \mathrm{~cm}^{2}$ and $1.6 \times 10^{-16} \mathrm{~cm}^{2}$. It seems that our ETD-based estimates of the $\sigma^{*}$ site cross section is in good agreement with expectations, based on DEA of both $\sigma^{*}$-orbitals and $\pi^{*}$-orbitals. In some contrast, our ETD-based estimates of the cross section of the Rydberg site is considerably smaller than the measured cross sections for species such as $\mathrm{H}_{3} \mathrm{O}^{+}$and $\mathrm{H}_{3} \mathrm{~S}^{+}$. These differences probably result from our having estimated the rate of formation of the lowest-energy $-\mathrm{NH}_{3}$ Rydberg state, whereas the dissociative recombination (DR) experiments (ref 32) likely form higher-energy Rydberg states that quickly decay radiationlessly to lower states that subsequently fragment. Therefore, it is probably best (i.e, combining our ETD estimates with the experimental DEA and DR data) to give the following estimates:

$$
\begin{gathered}
\sigma_{\sigma^{*}}=10^{-16}-10^{-17} \mathrm{~cm}^{2} \\
\sigma_{\text {Rydberg }}=10^{-14}-10^{-16} \mathrm{~cm}^{2}
\end{gathered}
$$

Thus, we are left concluding that ECD electrons probably attach to a positive site up to a thousand times more often than to Coulomb-stabilized $\mathrm{S}-\mathrm{S} \sigma^{*}$ sites, although the uncertainties in these estimates are large enough to merit well-designed experiments and theoretical studies to refine our predictions.

However, it is important to keep in mind that these attachment cross sections or rates are not directly proportional to the two rates of subsequent $\mathrm{S}-\mathrm{S}$ bond cleavage. After an electron exothermically attaches to a $\sigma^{*}$ site, the $\mathrm{S}-\mathrm{S}$ bond is promptly cleaved; however, when an electron attaches to a Rydberg site, the second and third steps in Scheme 2 must still occur before the $\mathrm{S}-\mathrm{S}$ bond ruptures. In particular, we note that only a fraction of the $\mathrm{H}$ atoms released or transferred from the $-\mathrm{NH}_{3}$ site will attach to the $\mathrm{S}-\mathrm{S}$ bond, unless the two sites are in relatively close proximity. If the $-\mathrm{NH}_{3}{ }^{+}$site is not initially in contact with the $\mathrm{S}-\mathrm{S}$ bond and is located a distance $R$ away, only a fraction of the released $H$ atoms will strike the $S-S$ bond. This fraction can be estimated knowing the length $R_{\mathrm{SS}}$ of the $\mathrm{S}-\mathrm{S}$ bond. A sphere of radius $R$ has an area of $\pi R^{2}$ and the $\mathrm{S}-\mathrm{S}$ bond region covers an area of approximately $\pi\left(R_{\mathrm{SS}} / 2\right)^{2}$, so the fraction of ejected $\mathrm{H}$ atoms likely to strike the $\mathrm{S}-\mathrm{S}$ bond is $\left(R_{\mathrm{SS}} / 2 R\right)^{2}$. Using values of $R_{\mathrm{SS}}=2 \AA$ and $R=4.8 \AA$ (the distance from the midpoint of the $\mathrm{S}-\mathrm{S}$ bond and the $\mathrm{N}$ atom in the equilibrium geometry of $\mathrm{H}_{3} \mathrm{C}-\mathrm{S}-\mathrm{S}-\mathrm{CH}_{2}-\mathrm{CH}_{2}-\mathrm{NH}_{3}{ }^{+}$), we estimate that $4 \%$ of the ejected $\mathrm{H}$ atoms would strike the $\mathrm{S}-\mathrm{S}$ bond for our model compound. This would then render the cross section for bond cleavage through attachment to the Rydberg site much closer in magnitude to that for attachment
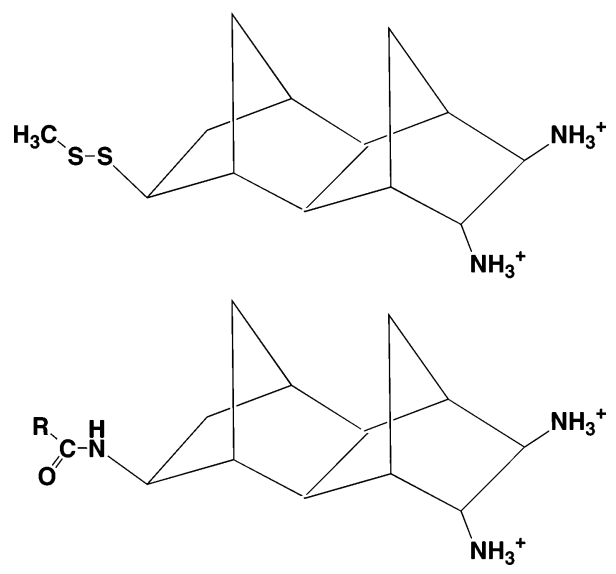

Figure 10. Potential test compounds in which the positive site and the $\mathrm{S}-\mathrm{S}$ or $\mathrm{C}=\mathrm{O}$ sites are held at relatively fixed distances.

to the $\sigma^{*}$ site for our model compound. Of course, if the $-\mathrm{NH}_{3}{ }^{+}$ site is initially in close contact with the $\mathrm{S}-\mathrm{S}$ bond, as assumed in the second variant of Schemes 1 and 2, a much higher fraction of the $\mathrm{H}$ atoms will probably strike the $\mathrm{S}-\mathrm{S}$ bond, and the Rydberg bond-cleavage cross section would then be expected to be 50-1000 times larger than that for the $\sigma^{*}$ bond cleavage.

\section{Summary and Generalizations}

In our opinion, the model classical trajectory and ab initio electronic structure calculations that we have conducted, combined with an analysis of known experimental cross sections for electron attachment, and assuming a resonant electrontransfer model for electron transfer dissociation (ETD), allows us to suggest the following for our model compound:

(1) ETD can occur at the positive site or the $S-S$ bond site at rates differing by an order of magnitude and favoring the positive site when $\mathrm{CH}_{3}{ }^{-}$is used as the anion.

(2) ETD to the Coulomb-stabilized bond site can be "turned off" through the use of an anion $\mathrm{A}^{-}$whose electron binding energy exceeds that of the $\mathrm{S}-\mathrm{S}$ bond site (ca. $2 \mathrm{eV}$ for our compound). The latter is determined by the intrinsic vertical electron attachment energy (ca. $0.9 \mathrm{eV}$ endothermic) of the bond site and the Coulomb stabilization energy provided by the cation's positive site (ca. $3 \mathrm{eV}$ ). Performing such experiments would offer a good way to determine whether direct $\mathrm{S}-\mathrm{S}$ bond site capture can occur as we have suggested.

(3) Electron capture dissociation (ECD) can also occur via capture at the positive site or the Coulomb-stabilized $\mathrm{S}-\mathrm{S}$ bond site; however, the cross section for capture at the positive site is probably $1-3$ orders of magnitude higher for our compound.

(4) ETD and ECD experiments should be performed on compounds in which the distance between the $-\mathrm{NH}_{3}{ }^{+}$positive site and the bond to be cleaved can be constrained to a narrow range. This would allow the competition between positive-site attachment followed by $\mathrm{H}$-atom-induced bond cleavage and Coulomb-assisted bond-attachment cleavage to be better addressed. Examples of the types of compounds that might be of use are shown in Figure 10.

In these compounds, the Coulomb stabilization energies produced at the $\mathrm{S}-\mathrm{S}$ and $\mathrm{C}=\mathrm{O}$ orbital sites would be 3.9 and $3.4 \mathrm{eV}$, respectively. ${ }^{36}$ Because the $\mathrm{S}-\mathrm{S} \sigma^{*}$-orbitals and $\mathrm{C}=\mathrm{O}$ $\pi^{*}$-orbitals have endothermic vertical attachment energies of ca. 1.0 and $2.8 \mathrm{eV}$, respectively, the Coulomb stabilization generated in such compounds should be sufficient to render the $\mathrm{S}-\mathrm{S}$ and $\mathrm{C}=\mathrm{O}$ bond attachment exothermic. On the other hand, the large distance and intervening steric blockage between the $\mathrm{S}-\mathrm{S}$ or $\mathrm{C}=\mathrm{O}$ bonds and any $\mathrm{H}$ atoms generated by electron 

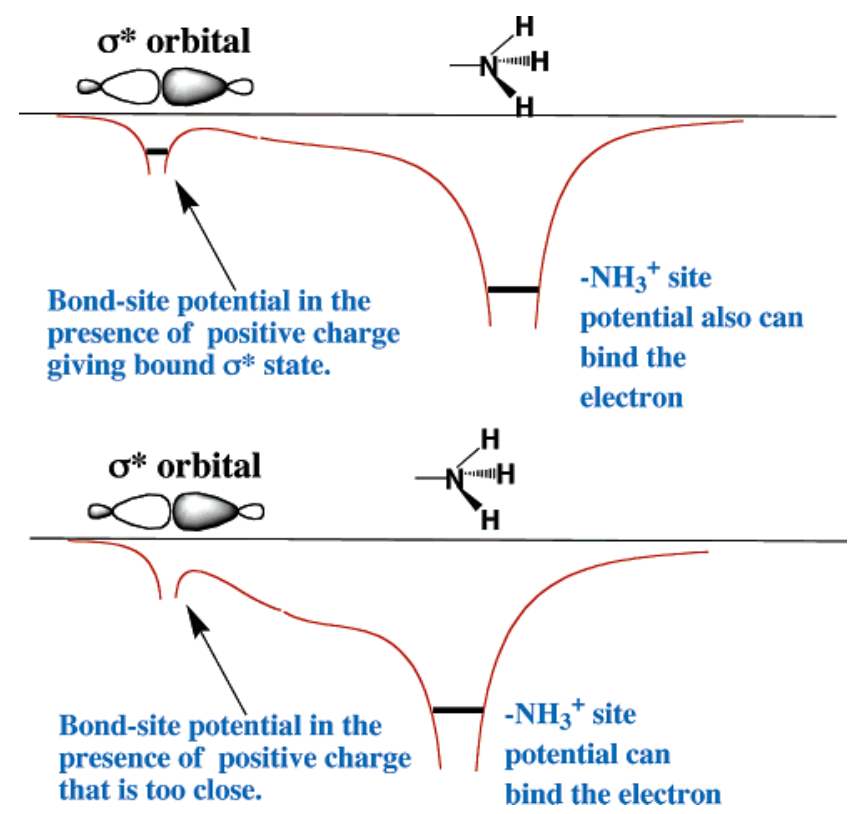

Figure 11. Bond-site and Rydberg-site combined potentials for cases in which the bond-site is rendered capable of binding (top) and when the positive site is too close to the bond site to bind (bottom).

attachment at the positive sites should make cleavage via Scheme 1 or 2 very inefficient.

Although our theoretical simulations of ETD and our extrapolation to ECD likely offer reasonable estimations of the relative rates, the uncertainties in these estimates are large enough to merit well-designed experiments and theoretical studies to refine our predictions, both of which we encourage.

Let us now attempt to extrapolate what we found for our model $\mathrm{MeSSCH}_{2} \mathrm{CH}_{2} \mathrm{NH}_{3}{ }^{+} \cdot \mathrm{CH}_{3}{ }^{-}$system to the cases of $\mathrm{S}-\mathrm{S}$ and $\mathrm{N}-\mathrm{C}_{\alpha}$ bond cleavages in peptides and proteins:

(1) First, we note that it is the $\mathrm{S}-\mathrm{S}$ and $\mathrm{N}-\mathrm{C}_{\alpha}$ bonds that would be most susceptible to Coulomb-assisted exothermic electron-attachment bond cleavage, because the corresponding $\mathrm{S}-\mathrm{S} \sigma^{*}$-orbitals and $\mathrm{C}=\mathrm{O} \pi^{*}$ orbitals are the lowest-lying antibonding orbitals in most peptides and proteins. The former require ca. $0.5-1.0 \mathrm{eV}$ of Coulomb stabilzation to render them amenable to exothermic electron attachment, and the latter require ca. $2.8 \mathrm{eV}$. This means that positive charges must be closer to the $\mathrm{C}=\mathrm{O}$ bonds (ca. $5 \AA$ ) to initiate $\mathrm{N}-\mathrm{C}_{\alpha}$ bond cleavage than to initiate $S-S$ bond cleavage $(15 \AA)$ via the Coulomb-assisted mechanism.

(2) For bonds that are very close to a positive site, the Coulomb potential can be so strong to make the total (i.e., bondsite plus Coulomb) potential no longer capable of supporting a bond-site-bound electronic state. In effect, the Coulomb potential pulls down the bond-site potential so much that the latter loses the barrier behind which an electron can attach. We illustrate this case and contrast it to the situation where Coulomb stabilization renders a bond site capable of electron binding in Figure 11.

In these cases, cleavage of bonds will occur by attachment to the Rydberg site (i.e., as in dissociative recombination) rather than by attachment to the bond site.

(3) ECD or ETD induced by capture at a positive site can be diminished if the positive site is far from the bond to be cleaved as, for example, it may be for the species shown in Figure 1. The diminuniton is expected to scale as $R^{-2}$ (where $R$ is the distance between the positive site and the bond to be cleaved). However, when the positive site is in close contact with the bond to be broken (e.g, through hydrogen bonding), cleavage through the $\mathrm{H}$-atom transfer mechanism of either of Schemes 1 or 2 will likely dominate, because the probabilities of attachment to the positive site exceed those for the stabilized-bond site.

Acknowledgment. The support of the National Science Foundation (NSF), through Grant No. CHE 0240387, is appreciated, as is significant computer time provided by the Center for High Performance Computing at the University of Utah and by the Academic Computer Center in Gdansk (TASK). We wish to thank Prof. P. Skurski of the University of Gdansk for several useful discussions and advice.

\section{References and Notes}

(1) (a) Zubarev, R. A.; Kelleher, N. L.; McLafferty, F. W. J. Am. Chem. Soc. 1998, 120, 3265-3266. (b) Zubarev, R. A.; Kruger, N. A.; Fridriksson, E. K.; Lewis, M. A.; Horn, D. M.; Carpenter, B. K.; McLafferty, F. W. J. Am. Chem. Soc. 1999, 121, 2857-2862. (c) Zubarev, R. A.; Horn, D. M.; Fridriksson, E. K.; Kelleher, N. L.; Kruger, N. A.; Lewis, M. A.; Carpenter, B. K.; McLafferty, F. W. Anal. Chem. 2000, 72, 563-573. (d) Zubarev, R. A.; Haselmann, K. F.; Budnik, B.; Kjeldsen, F.; Jensen, F. Eur. J. Mass Spectrom. 2002, 8, 337

(2) (a) Syka, J. E. P.; Coon, J. J.; Schroeder, M. J.; Shabanowitz, J.; Hunt, D. F. Proc. Nat. Acad. Sci. 2004, 101, 9528-9533. (b) Coon, J. J.; Syka, J. E. P.; Schwartz, J. C.; Shabanowitz, J.; Hunt, D. F. Int. J. Mass Spectrosc. 2004, 236, 33-42.

(3) For example, the addition of an electron to a protonated amine site $-\mathrm{NH}_{3}{ }^{+}$is exothermic by $3-4 \mathrm{eV}$, but the reaction $\mathrm{A}^{-}+-\mathrm{NH}_{3}{ }^{+} \rightarrow \mathrm{A}+$ $-\mathrm{NH}_{3}$ is less exothermic by an amount equal to the electron affinity (EA) of the A species.

(4) Much of the pioneering work aimed at understanding the mechanism(s) by which ECD operates has been reported in refs 1 and by the Turecek group. See, for example: (a) Syrstad, E. A.; Turecek, F. J. Phys. Chem. A 2001, A105, 11144-11115. (b) Turecek, F.; Syrstad, E. A. J. Am. Chem. Soc. 2003, 125, 3353-3369. (c) Turecek, F.; Polasek, M.; Frank, A.; Sadilek, M. J. Am. Chem. Soc. 2000, 122, 2361-2370. (d) Syrstad, E. A.; Stephens, D. D.; Turecek, F. J. Phys. Chem. A 2003, A107, 115. (e) Turecek, F. J. Am. Chem. Soc. 2003, 125, 5954. (f) Syrstad, E. A.; Truecek, F. Am. Soc. Mass. Spectrom. 2004, 16, 208-224. (This latter paper contains the most up-to-date discussion of the mechanism of Scheme 1b.)

(5) Uggerud, E. Int. J. Mass. Spectrom. 2004, 234, 45-50.

(6) Rydberg states of high principal quantum number are known to have long lifetimes and large radial extents.

(7) Hudgins, R. R.; Håkansson, K.; Quinn, J. P.; Hendrickson, C. L.; Marshall, A. G. In Proceedings of the 50th ASMS Conference on Mass Spectrometry and Allied Topics, Orlando, FL, June 2-6, 2002.

(8) Breuker, K.; Oh, H. B.; Lin, C.; Carpenter, B. K.; McLafferty, F. W. Proc. Natl. Acad. Sci. U.S.A. 2004, 101, 14011-14016. 3501 .

(9) Hudgins, R. R.; Jarrold, M. F. J. Am. Chem. Soc. 1999, 121, 3494-

(10) (a) Sawicka, A.; Skurski, P.; Hudgins, R. R.; Simons, J. J. Phys. Chem. B 2003, B107, 13505-13511. (We should note that, later, in ref 5, Uggerud also considered the possibility of direct electron attachment to SS bonds.) (b) Sawicka, A.; Berdys-Kochanska, J.; Skurski, P.; Simons, J. Int. J. Quantum Chem. 2005, 102, 838-846.

(11) To be more precise, we should say that the species formed when an electron is attached to the $\sigma^{*}$ orbital may have its energy differentially reduced, relative to the parent species that contains two electrons in the bonding $\sigma$-orbital, because of the Coulomb interaction energy difference associated with the $\sigma^{2} \sigma^{* 1}$ species and the parent $\sigma^{2}$ species interacting with the positive site(s).

(12) (a) Dezarnaud-Dandine, C.; Bournel, F.; Tronc, M.; Jones, D.; Modelli, A. J. Phys. B: At. Mol. Opt. Phys. 1998, 31, L497-L501. (b) Modelli, A.; Jones, D.; Distefano, G.; Tronc, M. Chem. Phys. Lett. 1991 181, 361-366.

(13) Berges, J.; Kassab, E.; Conte, D.; Adjadj, E.; Houee-Levin, C. J. Phys. Chem. A 1997, A101, 7809-7817.

(14) Sobczyk, M.; Anusiewicz, I.; Berdys-Kochanska, J.; Sawicka, A.; Skurski, P.; Simons, J. J. Phys. Chem. A 2005, A109, 250-258.

(15) Syrstad, E. A.; Turecek, F. J. Am. Soc. Mass Spectrom. 2005, 16, $208-224$.

(16) Bakken, V.; Helgaker, T.; Uggerud, E. Eur. J. Mass Spectrom. 2004, $10,625-638$.

(17) Case, D. A.; Pearlman, D. A.; Caldwell, J. W.; Cheatham, T. E., III; Wang, J.; Ross, W. S.; Simmerling, C. L.; Darden, T. A.; Merz, K. M.; Stanton, R. V.; Cheng, A. L.; Vincent, J. J.; Crowley, M.; Tsui, V.; Gohlke, H.; Radmer, R.; Duan, Y.; Pitera, J.; Massova, I.; Seibel, G. L.; Singh, U. C.; Weiner, P. K.; Kollman, P. A. AMBER 7, University of California, San Francisco, CA, 2002 
(18) Boyly, C. I.; Cieplak, P.; Cornell, W. D.; Kollman, P. A. J. Phys. Chem. 1993, 97, 10269-10280.

(19) This level of theory has been used successfully in the classic studies of dissociative electron attachment and through-bond electron transfer of for, example, Jordan, K. D.; Paddon-Row, M. N. Chem. Rev. 1992, 92, $395-410$.

(20) Kendall, R. A.; Dunning, T. H., Jr.; Harrison, R. J. J. Chem. Phys. 1992, 96, 6796

(21) Frisch, M. J.; Trucks, G. W.; Schlegel, H. B.; Scuseria, G. E.; Robb, M. A.; Cheeseman, J. R.; Montgomery, Jr., J. A.; Vreven, T.; Kudin, K. N.; Burant, J. C.; Millam, J. M.; Iyengar, S. S.; Tomasi, J.; Barone, V.; Mennucci, B.; Cossi, M.; Scalmani, G.; Rega, N.; Petersson, G. A.; Nakatsuji, H.; Hada, M.; Ehara, M.; Toyota, K.; Fukuda, R.; Hasegawa, J.; Ishida, M.; Nakajima, T.; Honda, Y.; Kitao, O.; Nakai, H.; Klene, M.; Li, X.; Knox, J. E.; Hratchian, H. P.; Cross, J. B.; Bakken, V.; Adamo, C.; Jaramillo, J.; Gomperts, R.; Stratmann, R. E.; Yazyev, O.; Austin, A. J.; Cammi, R.; Pomelli, C.; Ochterski, J. W.; Ayala, P. Y.; Morokuma, K.; Voth, G. A.; Salvador, P.; Dannenberg, J. J.; Zakrzewski, V. G.; Dapprich, S.; Daniels, A. D.; Strain, M. C.; Farkas, O.; Malick, D. K.; Rabuck, A. D.; Raghavachari, K.; Foresman, J. B.; Ortiz, J. V.; Cui, Q.; Baboul, A. G.; Clifford, S.; Cioslowski, J.; Stefanov, B. B.; Liu, G.; Liashenko, A.; Piskorz, P.; Komaromi, I.; Martin, R. L.; Fox, D. J.; Keith, T.; Al-Laham, M. A.; Peng, C. Y.; Nanayakkara, A.; Challacombe, M.; Gill, P. M. W.; Johnson, B.; Chen, W.; Wong, M. W.; Gonzalez, C.; Pople, J. A. Gaussian 03, Revision A.1; Gaussian, Inc., Wallingford CT, 2004.

(22) An analogous discussion could be made comparing the $\mathrm{C}=\mathrm{O} \pi^{*}$ orbital's attraction and that of a positive site elsewhere in a peptide or protein.

(23) Al-Khalili, A.; Thomas, R.; Ehlerding, A.; Heilberg, F.; Geppart, W. D.; Zhaunerchyk, V.; Uggerud, E.; Vedde, J.; Adlhart, C.; Semaniak, J.; Kaminska, M.; Zubarev, R. A.; Kjeldsen, F.; Andersson, P. U.; Österdahl, F.; Bednarska, V. A.; Paal, A. J. Chem. Phys. 2004, 121, 5700-5708.

(24) As will become clear soon, most of the energy available in the collisions that we are studying will come from converting the cation-anion Coulomb attraction energy to relative translational energy. The initial internal vibrational-rotational energy of the cation or anion will be a small fraction of the total energy and can therefore be ignored.

(25) (a) Landau, L. Phys. Z. Sowjetunion 1932, 2, 46. (b) Zener, C. Proc. R. Soc. London, Ser. A 1932, 137, 696. (c) Stueckelberg, E. C. G. Helv. Phys. Acta 1932, 5, 369-422.

(26) Barbier, L.; Djerad, M. T.; Cheret, M. Phys. Rev. A 1986, A34, $2710-2718$ 3675 .
(28) This approach is predicated on assuming one has two diabatic (i.e., having fixed orbital occupancy) states $\psi_{1}$ and $\psi_{2}$, whose diagonal Hamiltonian matrix elements $E_{1}=\left\langle\psi_{1} \mid \mathscr{T} \psi_{1}\right\rangle$ and $E_{2}=\left\langle\psi_{2} \mid \mathscr{\mathscr { T }} \psi_{2}\right\rangle$ describe their diabatic energies and whose off-diagonal element $\mathscr{T}_{12}=\left\langle\psi_{1} \mid \mathscr{T}_{4}\right\rangle$ gives their coupling. If these two states are allowed to interact and form two adiabatic states, the latter will have energies given by $E=\left\{1 / 2\left(E_{1}+\right.\right.$ $\left.\left.E_{2}\right) \mp 1 / 2\left[\left(E_{1}-E_{2}\right)^{2}+4 \mathscr{T}_{1,2}{ }^{2}\right]^{1 / 2}\right\}$. At the crossing region of $E_{1}$ and $E_{2}$, the two adiabatic solutions will differ by $2 \mathscr{T}_{1,2}$.

(29) Electron-cation and anion-cation collision cross sections are usually considerably greater than, for example, gas-kinetic cross sections, especially when the relative kinetic energies are low. It is the effect of the long-range Coulomb attractive potentials that makes these collision cross sections so large.

(30) It would probably be better to use a model compound in which the $\mathrm{S}-\mathrm{S}$ bond and the $-\mathrm{NH}_{3}{ }^{+}$sites are separated by more rigid units than methylene groups, so one could be more confident about knowing the distance between these two sites.

(31) The radial sizes of orbitals vary inversely as the square root of their electron binding energies. Because the Rydberg and $\sigma^{*}$ binding energies differ by a factor of 2 , the radial sizes of the corresponding orbitals will be similar.

(32) Vejby-Christensen, L.; Andersen, L. H.; Heber, O.; Kella, D.; Pedersen, H. B.; Schmidt, H. T.; Zajfman, D. Astrophys. J. 1997, 483, 531540.

(33) We choose this electron energy because it is characteristic of the low-energy ECD experiments to which we are trying to relate.

(34) Cicman, P.; Pelc, A.; Sailer, W.; Matejcik, S.; Scheier, P.; Märk, T. Chem. Phys. Lett. 2003, 371, 231-237. This cross section was determined for 1.1-eV electrons; it is known (see Klar, D.; Fabrikant, I.; Hotop, H. $J$. Phys. B 2001, B34, 3855-3878) that the cross section varies with electron energy $E$ approximately as $E^{-1 / 2}$. Therefore, for electrons that have kinetic energy in the $0.1-\mathrm{eV}$ range, as we are considering here, the cross section is expected to be somewhat larger than that stated here.

(35) Pearl, D. M.; Burrow, P. D.; Nash, J. J.; Morrison, H.; Nachtigallova, D.; Jordan, K. D. J. Phys. Chem. 1995, 99, 12379-12381.

(36) These values are obtained by simply adding the unscreened Coulomb potentials of the two positive sites at the center of the $\mathrm{S}-\mathrm{S}$ or $\mathrm{C}=\mathrm{O}$ bond. We have shown (for example, see Skurski, P.; Simons, J.; Wang, X.-B.; Wang, L.-S. J. Am. Chem. Soc. 2000, 122, 4499-4507) that there is little, if any, dielectric screening produced by bonds within a molecule. The dielectric screening would be substantial if the molecule were surrounded by a bulk material that has a significant dielectric constant. 